\title{
Lack of Evidence for Vesicular Glutamate Transporter Expression in Mouse Astrocytes
}

\author{
Dongdong Li, ${ }^{1 \star}$ Karine Hérault, ${ }^{1 \star}$ Kätlin Silm, ${ }^{2}$ Alexis Evrard, ${ }^{1}$ Sonja Wojcik, ${ }^{3}$ Martin Oheim, ${ }^{1}$ Etienne Herzog, ${ }^{2}$ \\ and Nicole Ropert ${ }^{1}$ \\ ${ }^{1}$ INSERM U603, CNRS UMR8154, Laboratoire de Neurophysiologie et Nouvelles Microscopies, PRES Sorbonne Paris Cité, Université Paris Descartes, Paris, \\ F-75006 France, 2INSERM U952, CNRS UMR7224, Laboratoire de Physiopathologie des Maladies du Système Nerveux Central, Université Pierre et Marie \\ Curie, Paris, F-75005 France, and ${ }^{3}$ Max-Planck-Institut für Experimentelle Medizin, Molekulare Neurobiologie, Göttingen, D-37075 Germany
}

The concept of a tripartite synapse including a presynaptic terminal, a postsynaptic spine, and an astrocytic process that responds to neuronal activity by fast gliotransmitter release, confers to the electrically silent astrocytes an active role in information processing. However, the mechanisms of gliotransmitter release are still highly controversial. The reported expression of all three vesicular glutamate transporters (VGLUT1-3) by astrocytes suggests that astrocytes, like neurons, may release glutamate by exocytosis. However, the demonstration of astrocytic VGLUT expression is largely based on immunostaining, and the possibility of nonspecific labeling needs to be systematically addressed. We therefore examined the expression of VGLUT1-3 in astrocytes, both in culture and in situ. We used Western blots and single-vesicle imaging by total internal reflection fluorescence microscopy in live cultured astrocytes, and confocal microscopy, at the cellular level in cortical, hippocampal, and cerebellar brain slices, combined with quantitative image analysis. Control experiments were systematically performed in cultured astrocytes using wild-type, VGLUT1-3 knock-out, VGLUT1 ${ }^{\text {Venus }}$ knock-in, and VGLUT2-EGFP transgenic mice. In fixed brain slices, we quantified the degree of overlap between VGLUT1-3 and neuronal or astrocytic markers, both in an object-based manner using fluorescence line profiles, and in a pixel-based manner using dual-color scatter plots followed by the calculation of Pearson's correlation coefficient over all pixels with intensities significantly different from background. Our data provide no evidence in favor of the expression of any of the three VGLUTs by gray matter protoplasmic astrocytes of the primary somatosensory cortex, the thalamic ventrobasal nucleus, the hippocampus, and the cerebellum.

\section{Introduction}

The concept of the tripartite synapse, which includes thin astrocytic processes ensheathing the presynaptic terminals and the postsynaptic spines, has received considerable attention because it confers an active role in information processing to the electrically silent astrocytes (for review, see Araque et al., 1999). In this scheme, astrocytes, which express G-protein-coupled receptors,

Received July 31, 2012; revised Jan. 11, 2013; accepted Jan. 15, 2013.

Author contributions: D.L., M.O., E.H., and N.R. designed research; D.L., K.H., K.S., A.E., E.H., and N.R. performed research;S.W. contributed unpublished reagents/analytic tools; D.L. analyzed data; D.L., M.O., E.H., and N.R. wrote the paper.

This work was supported by the Agence Nationale de la Recherche (P3N 09-044-02 and Optoglia R12009KK to U603; PSYVGLUT 09-MNPS-033 to UMR7224) and the European Union (FP6-STRP-2006-037897, AUTOSCREEN, and FP7-ERA-NET Neuron 09NEUR006). K.S. received a PhD fellowship from the French Research Ministry. We thank Diederick Moechars for VGLUT2 KO and Salah El Mestikawy for VGLUT3 KO. We thank Claire Mader and Christine Lamouroux for organizing the animal house, and Elke Schmidt and Fabrice Machulka for help handling the mice. Confocal imaging was done at the imaging platform of the Institut Fédératif de Recherche des Neurosciences (IFR 95) at Université Paris Descartes, and at the Service d'Imagerie Cellulaire of the IFR83 for Integrative Biology at Université Pierre et Marie Curie.

${ }^{*}$ D.L. and K.H. contributed equally to this work.

Correspondence should be addressed to either of the following: Nicole Ropert, INSERM U603, CNRS UMR8154, Laboratoire de Neurophysiologie et Nouvelles Microscopies, PRES Sorbonne Paris Cité, Université Paris, Descartes, Paris, F-75006 France, E-mail: nicole.ropert@parisdescartes.fr; or Etienne Herzog Interdisciplinary Institute for NeuroScience CNRS UMR 5297 Université de Bordeaux Victor Segalen, Bordeaux, F-33077 France, E-mail: etienne.herzog@u-bordeaux2.fr.

E. Herzog's present address: Interdisciplinary Institute for NeuroScience CNRS UMR 5297 Université de Bordeaux Victor Segalen, Bordeaux, F-33077 France.

DOI:10.1523/JNEUROSCI.3667-12.2013

Copyright $\odot 2013$ the authors $\quad 0270-6474 / 13 / 334434-22 \$ 15.00 / 0$ respond to neuronal activity by $\mathrm{Ca}^{2+}$ elevations and the subsequent release of gliotransmitters that in turn regulates the neuronal excitability and synaptic transmission (Perea et al., 2009). However, the mechanisms of gliotransmission and their physiological and pathological relevance are still controversial ( $\mathrm{Fi}-$ acco et al., 2009; Hamilton and Attwell, 2010; Nedergaard and Verkhratsky, 2012).

At the neuronal synapse, fast glutamate release relies on small vesicles carrying one vesicular glutamate transporter (VGLUT) for glutamate vesicular storage (Fremeau et al., 2004a). VGLUT1 (Bellocchio et al., 2000; Takamori et al., 2000), VGLUT2 (Fremeau et al., 2001; Herzog et al., 2001), and to a lesser extent VGLUT3 (Ruel et al., 2008; Seal et al., 2008), are markers of glutamatergic synapses (Fremeau et al., 2004a; Moriyama and Yamamoto, 2004). VGLUT3, which is mainly expressed by cholinergic, serotoninergic, and GABAergic neurons (Fremeau et al., 2002; Gras et al., 2002; Schäfer et al., 2002; Herzog et al., 2004; Somogyi et al., 2004; Gillespie et al., 2005), may contribute to glutamate cotransmission (Trudeau and Gutierrez, 2007; Hnasko and Edwards, 2012) and facilitate the vesicular storage of cotransmitters (Gras et al., 2008). Interestingly all VGLUTs have been reported to be expressed by astrocytes, suggesting that astrocytes like neurons can release glutamate by exocytosis (Hamilton and Attwell, 2010). Evidence for VGLUT expression comes from cultured astrocytes (Anlauf and Derouiche, 2005; Montana et al., 2004; Zhang et al., 2004; Crippa et al., 2006; Bowser and Khakh, 2007; Stenovec et al., 2007; Marchaland et al., 2008; Ni and Parpura, 2009), as well as in situ studies (Fremeau 
Table 1. Antibodies used for fluorescence immunostaining and Western blotting

\begin{tabular}{|c|c|c|}
\hline Experiments & Primary antibodies & Secondary antibodies ${ }^{a}$ \\
\hline \multicolumn{3}{|l|}{ Single staining } \\
\hline VGLUT1. Cultured cortical astrocytes, Fig. 1D-E & Rabbit (Rb) BN3L2Bf VGLUT1 (Herzog et al., 2001), 1/2000 & Alexa 488 or 555 Goat (G) anti Rb, 1/2000 \\
\hline \multicolumn{3}{|l|}{ Double staining } \\
\hline $\begin{array}{l}\text { VGLUT1 and S100 } \beta \text {. Cultured cortical astrocytes, Fig. } \\
1 B, C\end{array}$ & $\begin{array}{l}\text { Guinea pig (GP) VGLUT1, Millipore, Cat № AB5905, 1/4000 } \\
\text { and Rb S100 } \beta \text { Swant, 1/2000 }\end{array}$ & $\begin{array}{l}\text { Alexa } 488 \text { or } 555 \mathrm{G} \text { anti } \mathrm{GP}, 1 / 2000 \text { and Alexa } 488 \text { or } 555 \mathrm{G} \text { anti Rb, } \\
1 / 2000\end{array}$ \\
\hline VGLUT2 and GFAP. Cultured cortical astrocytes, Fig. $4 B$ & $\begin{array}{l}\text { GP VGLUT2, Millipore, Cat N }{ }^{\circ} \text { AB2251, 1/2000 and Mouse } \\
\text { (M) GFAP, Millipore, MAB360, 1/1000 }\end{array}$ & Alexa $633 \mathrm{G}$ anti $\mathrm{GP}, 1 / 500$ and Alexa $488 \mathrm{G}$ anti $\mathrm{M}, 1 / 500$ \\
\hline VGLUT3 and GFAP. Cultured cortical astrocytes, Fig. 5B & $\begin{array}{l}\text { Rb VGLUT3, SYSY, Cat N }{ }^{\circ} 135 \text { 203, 1/500 and M GFAP, } \\
\text { Millipore, Cat Nº MAB360, 1/2000 }\end{array}$ & Alexa $555 \mathrm{G}$ anti Rb, 1/2000 and Alexa $488 \mathrm{G}$ anti M, 1/2000 \\
\hline GLT-1 and AQ4. Slices from C57Bl/6J mice, Fig. 6D & $\begin{array}{l}\text { GP GLT-1, Frontier Science, Cat NAf810, 1/500 and Rb } \\
\text { AQP4, Sigma, Cat N} H P A 014784,1 / 500\end{array}$ & Alexa $633 \mathrm{G}$ anti GP, $1 / 500$ and Alexa $488 \mathrm{G}$ anti Rb, 1/500 \\
\hline $\begin{array}{l}\text { VGLUT1 and synapsin. Slices from C57BI/6J mice, Fig. } \\
7\end{array}$ & $\begin{array}{l}\text { GP VGLUT1, Millipore, Cat N AB5905, 1/4000 and Rb Syn- } \\
\text { apsin, SYSY, Cat N }{ }^{\circ} 106002,1 / 500\end{array}$ & Alexa $633 \mathrm{G}$ anti $\mathrm{GP}, 1 / 500$ and Alexa $488 \mathrm{G}$ anti Rb, 1/500 \\
\hline VGLUT1 and PSD95. Slices from C57BI/6J mice, Fig. 7 & $\begin{array}{l}\text { GP VGLUT1, Millipore, Cat N }{ }^{\circ} \text { AB5905, 1/4000 and M PSD95, } \\
\text { Abcam, Cat No }{ }^{\circ} \text { ab2723, 1/800 }\end{array}$ & Alexa $633 \mathrm{G}$ anti GP, $1 / 500$ and Alexa $488 \mathrm{G}$ anti M, 1/500 \\
\hline $\begin{array}{l}\text { VGLUT2 and synapsin. Slices from C57BI/6J mice, Fig. } \\
10\end{array}$ & $\begin{array}{l}\text { GP VGLUT2, Millipore, Cat N AB2251, 1/1000 and Rb Syn- } \\
\text { apsin, SYSY, Cat N }{ }^{\circ} 106002,1 / 500\end{array}$ & Alexa $633 \mathrm{G}$ anti $\mathrm{GP}, 1 / 500$ and Alexa $488 \mathrm{G}$ anti Rb, 1/500 \\
\hline VGLUT3 and GLT1. Slices from VGLUT3 K0 mice, Fig. 5 & $\begin{array}{l}\text { Rb VGLUT3, SYSY, Cat N } 135 \text { 203, 1/500 and GP GLT-1, } \\
\text { Frontier Science, Cat NAf810, 1/500 }\end{array}$ & Alexa $488 \mathrm{G}$ anti Rb, 1/500 and Alexa $633 \mathrm{G}$ anti GP, 1/500 \\
\hline \multicolumn{3}{|l|}{ Triple staining } \\
\hline $\begin{array}{l}\text { VGLUT1, synapsin and GFAP. Hippocampal astrocyte- } \\
\text { neuron coculture Fig. } 1 A\end{array}$ & $\begin{array}{l}\text { GP VGLUT1, Millipore, Cat No AB5905, 1/4000 and Rb Syn- } \\
\text { apsin, SYSY, Cat N }{ }^{\circ} 106002,1 / 500 \text { and M GFAP, Milli- } \\
\text { pore, Cat N }{ }^{\circ} \text { MAB360, 1/400 }\end{array}$ & $\begin{array}{l}\text { Alexa } 633 \mathrm{G} \text { anti GP, } 1 / 500 \text { and Alexa } 546 \mathrm{G} \text { anti } \mathrm{Rb}, 1 / 500 \text { and } \\
\text { Alexa } 488 \mathrm{G} \text { anti } \mathrm{M}, 1 / 500\end{array}$ \\
\hline $\begin{array}{l}\text { VGLUT2, synapsin and GFAP. Thalamic astrocyte- } \\
\text { neuron co-culture Fig. } 4 A\end{array}$ & $\begin{array}{l}\text { GP VGLUT2, Millipore, Cat N }{ }^{\circ} \text { AB2251, } 1 / 2000 \text { and M GFAP, } \\
\text { Millipore, Cat N }{ }^{\circ} \text { MAB360, } 1 / 2000 \text { or Rb GFAP, Abcam, } \\
\text { Cat N }{ }^{\circ} \text { ab7260, } 1 / 1000 \text { and Rb synapsin, SYSY, Cat N }{ }^{\circ} \\
106002,1 / 2000 \text { or M synapsin 1, SYSY, Cat N }{ }^{\circ} 106001 \\
\text { 1/1000 }\end{array}$ & $\begin{array}{l}\text { Alexa } 555 \mathrm{G} \text { anti GP, } 1 / 2000 \text { or Alexa } 633 \mathrm{G} \text { anti GP } 1 / 500 \text { and } \\
\text { Alexa } 488 \mathrm{G} \text { anti M, } 1 / 2000 \text { or Alexa } 546 \mathrm{G} \text { anti Rb } 1 / 500 \text { and } \\
\text { Cy5 } \mathrm{G} \text { anti Rb, } 1 / 2000 \text { or Alexa } 488 \mathrm{G} \text { anti M 1/500 }\end{array}$ \\
\hline $\begin{array}{l}\text { GFP, NeuN and } 5100 \beta \text {. Slices from VGLUT2 eGFP } \\
\text { mice, Fig. } 3 A\end{array}$ & $\begin{array}{l}\text { Chicken (Ch) GFP, Invitrogen, Cat N }{ }^{\circ} \mathrm{A} 10262,1 / 1000 \text { and M } \\
\text { NeuN, Millipore, Cat N }{ }^{\circ} \text { MAB377, } 1 / 500 \text { and Rb S100 } \beta \text {, } \\
\text { Abcam, Cat N ab52642, 1/500 }\end{array}$ & $\begin{array}{l}\text { Alexa } 488 \mathrm{G} \text { anti } \mathrm{Ch}, 1 / 500 \text { and Alexa } 633 \mathrm{G} \text { anti } \mathrm{M}, 1 / 500 \text { and } \\
\quad \text { Alexa } 546 \mathrm{G} \text { anti } \mathrm{Rb}, 1 / 500\end{array}$ \\
\hline $\begin{array}{l}\text { VGLUT1, S100 } \beta \text { and AQ4. Slices from C57BI/6J mice, } \\
\text { Fig. } 6 E \text {, Fig. } 7 D \text { and Fig. } 8 C, F\end{array}$ & $\begin{array}{l}\text { GP VGLUT1, Millipore, Cat N }{ }^{\circ} \text { AB5905, 1/4000 and Rb AQP4, } \\
\text { Sigma, Cat N }{ }^{\circ} H P A 014784,1 / 500 \text { and M S100b Abcam, } \\
\text { Cat N }{ }^{\circ} \text { ab4066, 1/200 }\end{array}$ & $\begin{array}{l}\text { Alexa } 633 \mathrm{G} \text { anti GP, } 1 / 500 \text { and Alexa } 546 \mathrm{G} \text { anti Rb, } 1 / 500 \text { and } \\
\quad \text { Alexa } 488 \mathrm{G} \text { anti } \mathrm{M}, 1 / 500\end{array}$ \\
\hline $\begin{array}{l}\text { VGLUT1, NeuN and S100 } \beta \text {. Slices from C57BI/6J mice, } \\
\text { Figs. 7, } 8\end{array}$ & $\begin{array}{l}\text { GP VGLUT1, Millipore, Cat N }{ }^{\circ} \text { AB5905, 1/4000 and M NeuN, } \\
\text { Millipore, Cat N }{ }^{\circ} \text { MAB377, } 1 / 500 \text { and Rb S100 } \beta \text { Abcam, } \\
\text { Cat N }{ }^{\circ} \text { ab52642, 1/500 }\end{array}$ & $\begin{array}{l}\text { Alexa } 633 \mathrm{G} \text { anti GP, } 1 / 500 \text { and Alexa } 488 \mathrm{G} \text { anti } \mathrm{M}, 1 / 500 \text { and } \\
\text { Alexa } 546 \mathrm{G} \text { anti } \mathrm{Rb}, 1 / 500\end{array}$ \\
\hline $\begin{array}{l}\text { VGLUT1, S100 } \beta \text { and GLT-1. Slices from C57BI/6J mice, } \\
\text { Figs. 6-8 }\end{array}$ & $\begin{array}{l}\text { GP VGLUT1, Millipore, Cat N }{ }^{\circ} \text { AB5905, 1/4000 and M S100 } \beta \\
\text { Abcam, Cat N }{ }^{\circ} \text { ab4066, 1/200 and Rb GLT-1, Abcam, Cat } \\
\text { N }^{\circ} \text { ab41621, } 1 / 500\end{array}$ & $\begin{array}{l}\text { Alexa } 633 \mathrm{G} \text { anti } \mathrm{GP}, 1 / 500 \text { and Alexa } 488 \mathrm{G} \text { anti } \mathrm{M}, 1 / 500 \text { and } \\
\quad \text { Alexa } 546 \mathrm{G} \text { anti } \mathrm{Rb}, 1 / 500\end{array}$ \\
\hline $\begin{array}{l}\text { VGLUT1 and S100 } \beta \text {. Slices from VGLUT1 }{ }^{\text {Venus }} \mathrm{KI} \text { mice, } \\
\text { with and without GFP antibody, Fig. } 9\end{array}$ & $\begin{array}{l}\text { GP VGLUT1, Millipore, Cat N }{ }^{\circ} \text { AB5905, } 1 / 4000 \text { and Rb } \\
\text { S100 } \beta \text { Abcam, Cat } N^{\circ} \text { ab52642, 1/500 and Ch GFP, } \\
\text { Invitrogen, Cat N }{ }^{\circ} \text { A10262, 1/1000 }\end{array}$ & $\begin{array}{l}\text { Alexa } 633 \mathrm{G} \text { anti GP, } 1 / 500 \text { and Alexa } 546 \mathrm{G} \text { anti Rb, } 1 / 500 \text { and } \\
\quad \text { Alexa } 488 \mathrm{G} \text { anti } \mathrm{Ch}, 1 / 500\end{array}$ \\
\hline $\begin{array}{l}\text { VGLUT1 and GLT-1. Slices from VGLUT1 }{ }^{\text {Venus }} \text { KI mice, } \\
\text { with and without GFP antibody Fig. } 9\end{array}$ & $\begin{array}{l}\text { GP VGLUT1, Millipore, Cat N }{ }^{\circ} \text { AB5905, 1/4000 and Rb } \\
\text { GLT-1, Abcam, Cat N }{ }^{\circ} \text { ab41621, 1/500 and Ch GFP, Invit- } \\
\text { rogen, Cat N }{ }^{\circ} \text { A10262, 1/1000 }\end{array}$ & $\begin{array}{l}\text { Alexa } 633 \mathrm{G} \text { anti GP, } 1 / 500 \text { and Alexa } 546 \mathrm{G} \text { anti } \mathrm{Rb}, 1 / 500 \text { and } \\
\quad \text { Alexa } 488 \mathrm{G} \text { anti } \mathrm{Ch}, 1 / 500\end{array}$ \\
\hline $\begin{array}{l}\text { VGLUT2, NeuN and S100 } \beta \text {. Slices from C57BI/6J mice, } \\
\text { Fig. } 10\end{array}$ & $\begin{array}{l}\text { GP VGLUT2, Millipore, Cat N }{ }^{\circ} \text { AB2251, 1/1000 and M NeuN, } \\
\text { Millipore, Cat N }{ }^{\circ} \text { MAB377, 1/500 and Rb S100 } \beta \text { Abcam, } \\
\text { Cat N }{ }^{\circ} \text { ab52642, } 1 / 500\end{array}$ & $\begin{array}{l}\text { Alexa } 633 \mathrm{G} \text { anti } \mathrm{GP}, 1 / 500 \text { and Alexa } 488 \mathrm{G} \text { anti } \mathrm{M}, 1 / 500 \text { and } \\
\quad \text { Alexa } 546 \mathrm{G} \text { anti } \mathrm{Rb}, 1 / 500\end{array}$ \\
\hline $\begin{array}{l}\text { VGLUT2, S100 } \beta \text { and GLT-1. Slices from C57BI/6J mice, } \\
\text { Figs. } 6,10\end{array}$ & 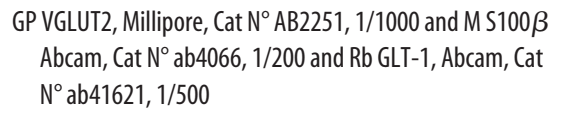 & $\begin{array}{l}\text { Alexa } 633 \mathrm{G} \text { anti } \mathrm{GP}, 1 / 500 \text { and Alexa } 488 \mathrm{G} \text { anti } \mathrm{M}, 1 / 500 \text { and } \\
\quad \text { Alexa } 546 \mathrm{G} \text { anti } \mathrm{Rb}, 1 / 500\end{array}$ \\
\hline $\begin{array}{l}\text { VGLUT3, S100 } \beta \text { and GLT-1. Slices from C57BI/6J mice, } \\
\text { Figs. } 6,11\end{array}$ & $\begin{array}{l}\text { Rb VGLUT3, SYSY, Cat N } 135 \text { 203, 1/500 and GP GLT-1, } \\
\text { Frontier Science, Cat NAf810, 1/500 and M S100 } \beta \\
\text { Abcam, Cat Nªb4066, 1/200 }\end{array}$ & $\begin{array}{l}\text { Alexa } 546 \mathrm{G} \text { anti } \mathrm{Rb}, 1 / 500 \text { and Alexa } 633 \mathrm{G} \text { anti GP, } 1 / 500 \text { and } \\
\text { Alexa } 488 \mathrm{G} \text { anti } \mathrm{M}, 1 / 500\end{array}$ \\
\hline \multicolumn{3}{|l|}{ Western blotting } \\
\hline VGLUT1 Western blot, Fig. $1 F$ & Rb BN3L2Bf VGLUT1 (Herzog et al., 2001), 1/5000 & IRDye $800 \mathrm{G}$ anti Rb (Rockland), 1/5000 \\
\hline VGLUT1 Western blot, Fig. 1G,H & GP VGLUT1, Millipore, Cat N AB5905, 1/4000 & IRDye $800 \mathrm{G}$ anti Rb (Rockland), 1/5000 \\
\hline VGLUT2 Western blot, Fig. $4 C$ & GP VGLUT2, Millipore, Cat N AB2251, 1/5000 & IRDye $800 \mathrm{G}$ anti GP (Rockland), 1/5000 \\
\hline VGLUT3 Western blot, Fig. $5 \mathrm{C}$ & Rb VGLUT3, SYSY, Cat Nº 135 203, 1/2000 & IRDye $800 \mathrm{G}$ anti Rb (Rockland), 1/5000 \\
\hline
\end{tabular}


Table 2. Combinations of excitation wavelengths and filters

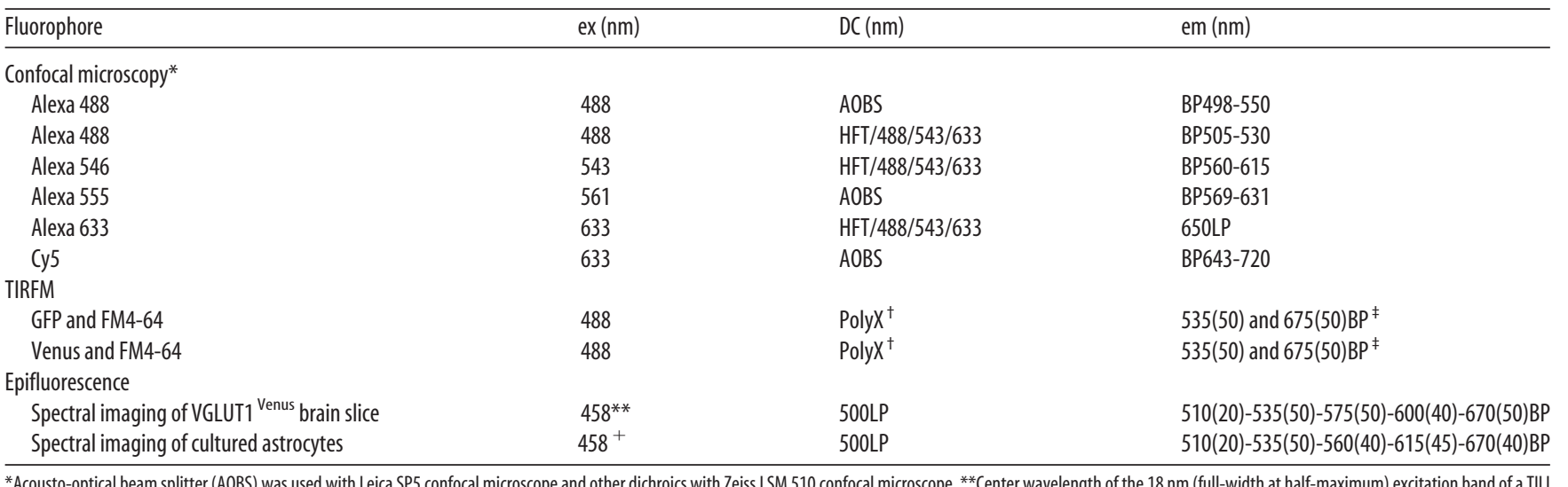

*Acousto-optical beam splitter (AOBS) was used with Leica SP5 confocal microscope and other dichroics with Zeiss LSM 510 confocal microscope. **(enter wavelength of the $18 \mathrm{~nm}$ (full-width at half-maximum) excitation band of a TILL polychrome II tunable light source. ${ }^{\dagger}$ PolyX, custom dual dichroic mirror with 488/568/NIR reflection bands and low ripple high-transmission elsewhere (AHF Analysentechnik). ${ }^{\ddagger}$ Denotes filters for simultaneous view with a custom dual-view device. DC, dichroic; ex, excitation wavelength; em, emission filter; TIRFM, total internal reflection fluorescence microscopy.

et al., 2002; Bezzi et al., 2004; Platel et al., 2010; Bergersen et al., 2012; Ormel et al., 2012b). Evidence is largely based on immunostaining and remains controversial because other authors failed to confirm astrocytic VGLUT expression (Hayashi et al., 2001; Graziano et al., 2008; Restani et al., 2011), raising the possibility that immunostaining might be compromised by nonspecific labeling (Fritschy, 2008). This concern has been fueled by the observation that, unlike synaptic glutamate release, glutamate release from astrocytes is not affected by a VGLUT-dependent effect of acetoacetate (Juge et al., 2010). Furthermore, a transcriptome analysis was unable to detect the VGLUT1 and VGLUT2 mRNAs in astrocytes (Cahoy et al., 2008). Finally, our previous study shows that anion channels rather than vesicular exocytosis mediate glutamate release by astrocytes in culture (Li et al., 2012). Hence, we decided to reexamine the expression of VGLUT1-3 proteins in astrocytes, both in culture and in situ.

We studied the VGLUT1-3 protein expression at the single vesicle level in cultured astrocytes using total internal reflection fluorescence microscopy (TIRFM), and at the cellular level in the cortical, hippocampal, and cerebellar cortex of fixed brain slices using confocal microscopy. Control experiments using immunostaining and VGLUT1-3 knock-out (KO) mice were performed. The expression of VGLUT1-2 in astrocytes was also investigated using VGLUT1 ${ }^{\text {Venus }}$ knock-in (KI) (Herzog et al., 2011), and VGLUT2-EGFP transgenic (Tg) mouse lines.

\section{Materials and Methods}

All experiments followed the European Union and institutional guidelines for the care and use of laboratory animals (Council directive 86/ 609EEC). Previous work has described the VGLUT1 KO (Wojcik et al., 2004), VGLUT2 KO (Moechars et al., 2006), VGLUT3 KO (Gras et al., 2008), and VGLUT1 ${ }^{\text {Venus }}$ KI (Herzog et al., 2011) mouse lines. The Bac Tg VGLUT2-EGFP mouse line [Tg(Slc17a6-EGFP)FY115Gsat \#11835UCD] was provided by the Mutant Mouse Regional Resource Center (Gong et al., 2003). The colony was maintained locally by crossing the heterozygous (HZ) mice with wild-type (WT) NMRI mice. Combinations of the primary and secondary antibodies used for fluorescence immunostaining and Western blotting are listed in Table 1. The combinations of excitation wavelengths (ex), dichroic (DC), and emission filters (em) used are listed in Table 2.

Cell preparation and immunofluorescence. Cortical or hippocampal astrocytes were prepared from newborn P0-P1 (P0 being the day of birth) NMRI mice of either sex, embryonic E18 (E0 being the day of mating) VGLUT2 KO of either sex, and P0 VGLUT1 KO and P0 VGLUT3 KO mice of either sex as previously described (Li et al., 2009). Briefly, the neocortex or the hippocampus was dissected and mechanically dissociated. Cells were plated and maintained in Petri dishes during 1 week to reach confluence before their transfer onto coverslips (\#1, BK-7, $25 \mathrm{~mm}$ diameter, Marienfeld Superior, Thermo Fisher Menzel-Gläser). Coverslips (12 mm diameter) were used for immunostainings. Cells were plated in plastic Petri dishes for Western blot analysis. Cultured astrocytes were maintained $10-15 \mathrm{~d}$ in vitro (DIV) before fixation. Cortical and thalamic astrocyte/neuron cocultures were isolated from E16-E17 VGLUT2 KO mice of either sex. Hippocampal astrocyte/neuron cocultures were prepared from P0 VGLUT1 KO mice of either sex. Cells were seeded on poly-D-lysine-treated coverslips. Thalamic cocultures were maintained in a medium containing DMEM-F12 supplied with 5\% fetal bovine serum (FBS), 1.3\% D-glucose $45 \%$, serum extender (1/1000), and penicillin/streptomycin (1/500). Cortical and hippocampal cocultures were maintained in a minimum essential medium with $10 \%$ FBS, $1 \%$ L-glutamine, $1.3 \% \mathrm{D}$-glucose $45 \%, 1 \%$ sodium pyruvate, $2 \% \mathrm{~B} 27$, and penicillin/streptomycin (1/1000). Cells were maintained in half of this serum and half of medium of primary astrocytes containing growth factors for neurons. Astrocyte/neuron cocultures were maintained 10-15 DIV before fixation. Cell media and supplements were from Invitrogen.

For immunofluorescence, astrocytes and astrocyte/neuron cocultures were treated with 4\% paraformaldehyde (PFA; EMS 15710; Electron Microscopy Services) for $10 \mathrm{~min}$ at room temperature (RT; $22-23^{\circ} \mathrm{C}$ ). After permeabilization and blockage of unspecific sites with PBS $1 \mathrm{X}$ (Sigma, P4417), 1\% Triton X-100, and 4\% normal goat serum (NGS; $1 \mathrm{~h}$, RT; Gibco, 16210-064), the cells were probed with the respective primary antibodies in the same solution overnight at $4^{\circ} \mathrm{C}$. After being washed with PBS IX three times at RT, cells were incubated with secondary antibodies $(2 \mathrm{~h}, \mathrm{RT})$. The same fluorophore combinations were used in all experiments to allow for direct comparison and exclude detection bias (Table 1). After three final washes (PBS, $10 \mathrm{~min}, \mathrm{RT}$ ), cells were mounted with Mowiol 4-88 (Calbiochem) onto microscope slides. Antibody specificity was controlled for by omitting the primary antibody and by using $\mathrm{KO}$ mice when available. Triple-immunofluorescence images of VGLUT1, synapsin, and glial fibrillary acidic protein (GFAP) in hippocampal astrocyte/neuron cocultures were acquired using a confocal laser-scanning microscope (Axiovert LSM 510; Carl Zeiss) equipped with $\mathrm{Ar}^{+}$(488, 543 $\mathrm{nm})$ and $\mathrm{HeNe}(633 \mathrm{~nm})$ gas lasers and multi-alkali side-on meshless photomultiplier tubes (PMTs; R6357; Hamamatsu), using a ×63/NA 1.4 Plan-Neofluar oil objective. Some images of cultured cells (as indicated in the figure legends) were acquired with another confocal laser-scanning microscope (Leica SP5 Microsystems) using a ×63/NA 1.32 PL APO oil objective.

Immunofluorescence of slice preparations. Adult (8 weeks) C57BL/6J WT of either sex, male VGLUT2-EGFP, VGLUT3 KO of either sex, and male VGLUT1 $1{ }^{\text {Venus }}$ KI mice were anesthetized by intraperitoneal injection of pentobarbital $(20 \mathrm{mg} / \mathrm{kg})$. Animals were perfused with intracardiac PBS 1X to remove blood cells and subsequently with 4\% PFA for fixation. The brains were removed and postfixed overnight at $4^{\circ} \mathrm{C}$ in $4 \%$ PFA. After rinsing in PBS 1X, the brains were conserved in PBS 1X. Thin 

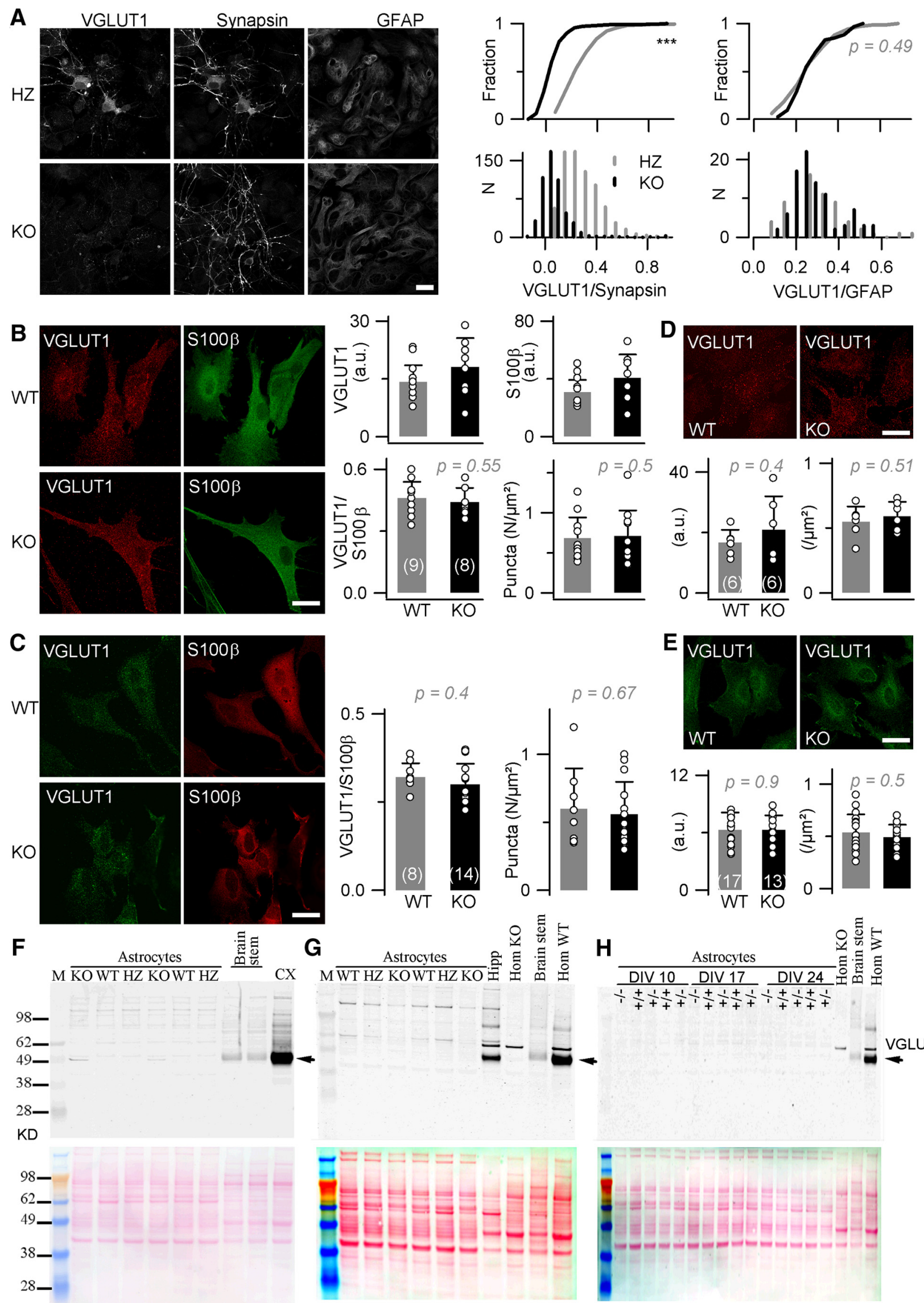

Figure 1. Astrocytes in culture do not express VGLUT1. A, Left, Confocal images of hippocampal astrocyte/neuron cocultures prepared from VGLUT1 HZ and KO mice and immunolabeled with antibodies against VGLUT1, synapsin, and GFAP. VGLUT1 fluorescence was seen in HZ but not in KO preparations. Right, The neuronal VGLUT1 fluorescence, quantified as (Figure legend continues.) 
(45 $\mu \mathrm{m})$ coronal slices were cut using a vibratome (VT1000S; Leica). After permeabilization with 1\% Triton X-100 (Sigma, T9284) and blockade of the unspecific sites with $4 \%$ NGS ( $1 \mathrm{~h}, \mathrm{RT}$ ), slices were stained with primary antibodies in a PBS $1 \mathrm{X}$ solution with $0.2 \%$ Triton X-100 and $2 \%$ NGS for overnight at $4^{\circ} \mathrm{C}$. Slices were then washed with PBS three times at RT and incubated with secondary antibodies (PBS 1X, 2\% NGS, $1 \mathrm{~h}$, $\mathrm{RT}$ ). After three final washes (PBS 1X, $10 \mathrm{~min}$ at RT) the slices were mounted in Mowiol 4-88 onto microscope slides and sealed with coverslips. Fluorescence images were collected with a Zeiss LSM 510 confocal microscope. Overviews were taken with $\times 10$ /NA 0.3 or $\times 20 / \mathrm{NA} 0.5$ air objectives. Single confocal sections taken with the $\times 63 /$ NA 1.4 PlanNeoFluar oil-immersion objective were used for colocalization analysis (see below). The confocal pinhole was systematically set to 0.8 Airy units to maximize axial resolution rather than the signal intensity. Sequential acquisitions were made to minimize cross-excitation. For each channel, the laser power, offset, and PMT gain were adjusted using a cold/graylevel/hot look-up table to avoid under exposure and saturation. Levels of autofluorescence and detected back-scattered excitation light were found negligible at the laser powers used for acquisition (typically $<10 \%$ power of the $30 \mathrm{~mW}$ available at $488 \mathrm{~nm}$ and $5 \mathrm{~mW}$ available at $633 \mathrm{~nm}$, and $<60 \%$ of the $1 \mathrm{~mW}$ of the $543 \mathrm{~nm}$ line, respectively).

Western blotting. Western blotting was performed on pure astrocyte cultures, primary neuron cultures, and tissue homogenates of VGLUTexpressing regions of the mouse brain of either sex with $5 \mu \mathrm{g}$ of protein loaded per lane. Astrocytes were cultured from two independent litters of either sex from each mouse line and lysed 2 weeks after culturing. Samples were loaded on precast NuPAGE Novex 10\% Bis-Tris Midi Gels (WG1202BOX; Invitrogen), migrated in NuPAGE MES-SDS Running Buffer (NP0002; Invitrogen), and transferred to nitrocellulose membranes (LC2009; Invitrogen) in Tris-borate buffer. IRDye 680/800 coupled secondary antibodies were used for semiquantitative detection and blots were exposed to reveal all signals, including background bands. Membranes were scanned using Odyssey infrared imaging system (LI-COR). Ponceau S staining was used for assessing the correct loading of samples as the heterogeneity in protein sources prevented us from using internal loading controls with confidence.

Combined multispectral epifluorescence and TIRF live-cell imaging. A custom-built inverted microscope (Nadrigny et al., 2006; Li et al., 2008) was used for bright-field polychromatic epifluorescence (EPI) imaging and through-the-objective TIRF imaging using a PlanApo TIRF $\times 60 / \mathrm{NA}$ 1.45 oil objective (Olympus). A Polychrome II light source (TILL Photonics) provided tunable narrowband $(18 \mathrm{~nm}$ full-width at halfmaximum) EPI illumination. The 488 and $568 \mathrm{~nm}$ lines used for TIRFM were isolated from the beam of an $\mathrm{Ar}^{+} / \mathrm{Kr}^{+}$multiline gaz laser (CVI; Melles Griot) with an acousto-optical tunable filter (AA.Opto) and directed onto the glass/water interface at a supercritical angle. We estimated the effective penetration depth of the order of $200 \mathrm{~nm}$ (Nadrigny et al., 2007). Fluorescence images were further magnified $(\times 2)$ and projected on an electron multiplying charge-coupled device (EMCCD; QuantEM 512; Princeton Instruments). All devices were controlled by MetaMorph 7.0. The effective pixel size in the sample plane was $133 \mathrm{~nm}$.

(Figure legend continued.) the ratio of VGLUT1/synapsin, was significantly smaller in VGLUT1 $\mathrm{KO}$ than $\mathrm{HZ}$ cell preparations. The VGLUT1 fluorescence of astrocytes, quantified as the ratio of VGLUT1/GFAP, was weak and similar in VGLUT1 $\mathrm{KO}$ and HZ cell preparations. $\boldsymbol{B}$, Confocal images of pure cortical astrocytes in culture immunolabeled with antibodies against VGLUT1 and S100 $\beta$. The VGLUT1 fluorescence was similar for astrocytes prepared from VGLUT1 KO and WT mice. Swapping the secondary antibodies ( $(\boldsymbol{)}$, using another VGLUT1 primary antibody (D), and swapping again the secondary antibodies $(\boldsymbol{E})$ did not change the results (see Table 1 ). $\boldsymbol{F}$, Western blot analysis of VGLUT1 expression by pure cultured cortical astrocytes from WT and VGLUT1 $\mathrm{KO}$ and HZ mice. Control VGLUT1 signal was obtained from brainstem and cortical tissue (Cx). Correct loading of samples is shown in the Ponceau S staining (below). Although we can detect weak VGLUT1 expression from brainstem tissue, we were not able to detect any specific signal from the astrocyte cultures (above). G, Lack of specific VGLUT1 band found for pure astrocyte cultures by Western blot with a different primary antibody (Millipore). Hipp, hippocampal coculture; Hom, whole-brain homogenate. $\boldsymbol{H}$, Western blot analysis of VGLUT1 expression in pure astrocyte cultures maintained 10, 17, and 24 DIV. Scale bars, $20 \mu \mathrm{m}$.
A custom image splitter permitted the simultaneous acquisition of dualchannel fluorescence on the same EMCCD camera chip. For emission spectral imaging, five emission spectral images were acquired upon 458 $\mathrm{nm}$ EPI excitation sequentially through narrow bandpass emission filters housed in a motorized filter wheel (details in Table 2).

Astrocytes were imaged 2-6 d after their transfer into secondary culture. All cultures were maintained at $37^{\circ} \mathrm{C}$ in a humidified $5 \% \mathrm{CO}_{2}$ atmosphere. VGLUT1-Venus $(1.4 \mu \mathrm{g} / \mu \mathrm{l})$ was transfected into cultured astrocytes using Lipofectamine 2000 (Invitrogen) following standard protocols. During imaging at RT, the cells were constantly perfused at $0.5-1 \mathrm{ml} / \mathrm{min}$ with extracellular solution containing the following (in $\mathrm{mm}$ ): $140 \mathrm{NaCl}, 5.5 \mathrm{KCl}, 1.8 \mathrm{CaCl}_{2}, 1 \mathrm{MgCl}_{2}, 20$ glucose, and 10 HEPES, $\mathrm{pH} 7.3$ was adjusted with $\mathrm{NaOH}$. Astrocytic lysosomes were labeled with the red-fluorescent styryl pyridinium dye FM4-64 (Invitrogen; $6.7 \mu \mathrm{M}$, $15 \mathrm{~min}$ ), and rinsed for $30 \mathrm{~min}$ with dye-free solution before imaging ( $\mathrm{Li}$ et al., 2008).

Colocalizaton analysis. We first assessed colocalization among different fluorescent markers using morphological landmarks, by drawing line profiles across morphologically identified neuronal and astrocytic processes. In addition to this object-based colocalization analysis, we systematically calculated pixel-based descriptors, incorporating the intensity information of all image pixels that had an intensity significantly different from background (see below). An intuitive way to see if a given pixel carries both fluorophores is a scatter plot in which the normalized intensity $F / F_{\max }$ is graphed pixelwise in a $2 \mathrm{D}$ histogram. Pixels in which both dyes are detected at the same $F / F_{\max }$ lay on a straight line from the origin to $(1,1)$. Image noise or variable labeling ratios add noise to this pattern, but points are still symmetrically spread about the $45^{\circ}$ line. However, albeit commonly used, these plots are difficult to interpret, because pixels with similar fluorophore ratios superimpose and obstruct each other when analyzing large images. Thus, the graphical impression of such pixel-dense scatter plots can be misleading. We therefore developed a density-encoded scatter plot in which the pixel abundance at a given intensity $\left(F_{1} / F_{1, \max }(i)\right.$, $\left.F_{2} / F_{2 \text { max }}(i)\right)$ is pseudocolor encoded from blue (few pixels) to red (many pixels). Thus, in addition to representing intensity ratios, this density-encoded scatter permits the visualization of the information contained in the ensemble of pixels. We also systematically measured the mean and standard deviation (SD) of the background signal and identified intensity regions on the scatter plot that contain intensity data significantly different from background (mean $+3 \mathrm{SD}$ ).

To compare fluorescent images, we calculated Pearson's correlation coefficient $r_{12}$ as follows:

$$
r_{12}=\frac{\sum_{i}^{N}\left(F_{1}(i)-\left\langle F_{1}\right\rangle_{\forall i}\right)\left(F_{2}(i)-\left\langle F_{2}\right\rangle_{\forall i}\right)}{\sqrt{\sum_{i}^{N}\left(F_{i}(i)-\left\langle F_{1}\right\rangle_{\forall i}\right)^{2} \cdot \sum_{i}^{N}\left(F_{2}(i)-\left\langle F_{2}\right\rangle_{\forall i}\right)^{2}}},
$$

where $F(i)$ represents the fluorescence intensity of each pixel $i$ and $F 1$ and $F 2$ the average over all $N$ pixels of the component images 1 and 2, respectively. $N$ is the total number of pixels in each image. This method has the advantage of taking into account both the image background and the specific labeling, and allowing a comparison of images with different average signal intensities. In fact, $r_{12}$ measures, for both color channels, the excursion of the pixel intensity from the mean signal. Background intensities were determined on the same image from at least five small regions of interest (ROIs; ranging from $2 \times 2 \mu \mathrm{m}$ to $5 \times 5 \mu \mathrm{m}$ ) devoid of fluorescent objects, e.g., outside the cell contour in culture, or within unlabeled cell nuclei in slices. Colocalization parameters were calculated from pixels the intensity of which exceeded the mean of the background by three times its SD. This intensity limit is shown as horizontal and vertical lines on the scatter plots (see Figs. $7 B$, $10 C$ ). The meaningful upper (i.e., positive control, +CTR) and lower bound (negative control, -CTR) of $r_{12}$ values (Li et al., 2008) were determined by performing dual-color immunostaining with antibodies against two presynaptic proteins, VGLUT1 and synapsin (Huttner et al., 1983), and against VGLUT1 and PSD-95, a postsynaptic density scaffolding protein selectively expressed by the excitatory synapses (Hunt et al., 1996; Heller et al., 2012), respectively.

To further demonstrate the significance of our colocalization analysis, we artificially introduced a variable pixel shift between images acquired in dif- 
A
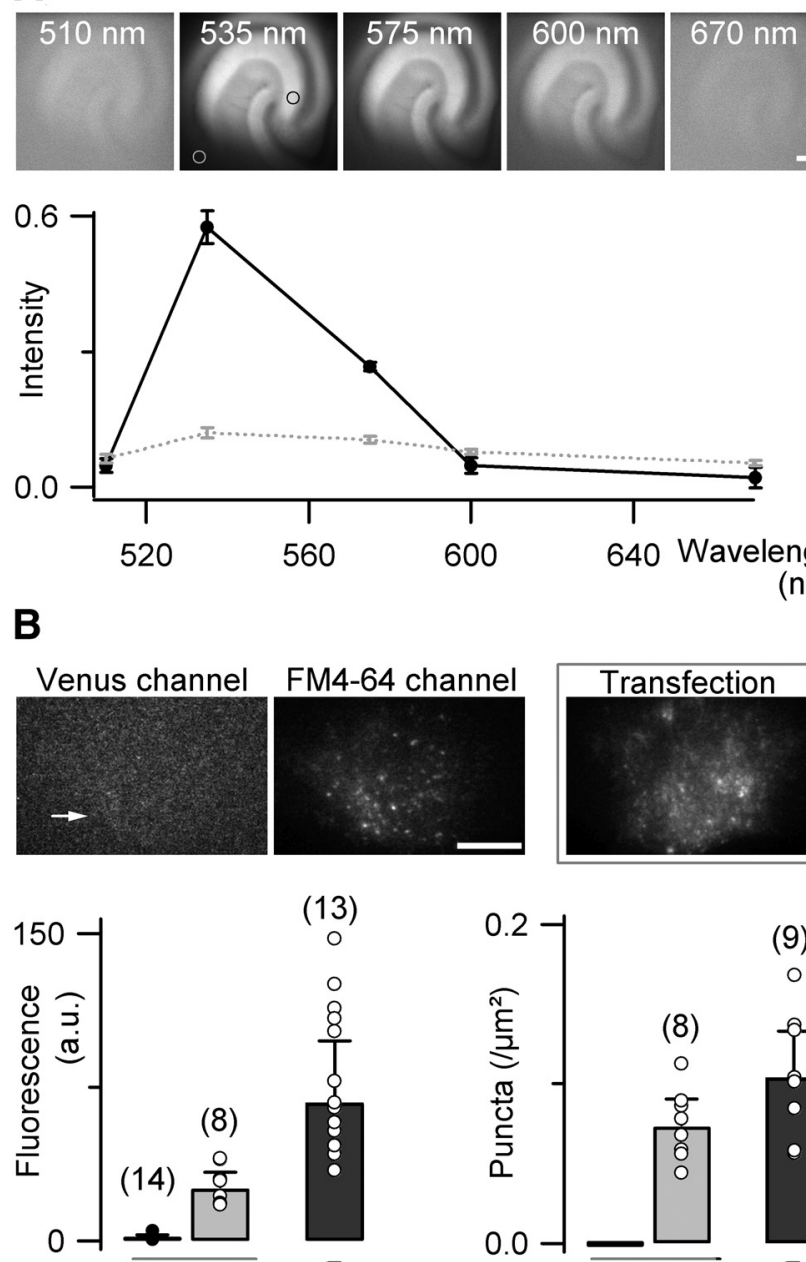

$(13)$
0

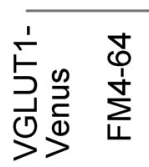

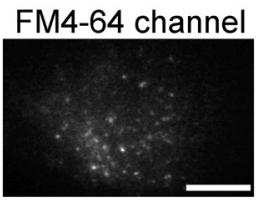

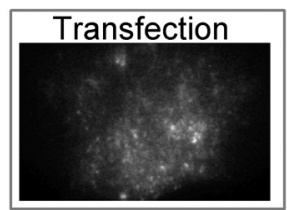

$(\mathrm{nm})$

C

$510 \quad 535 \quad 560$

615

670
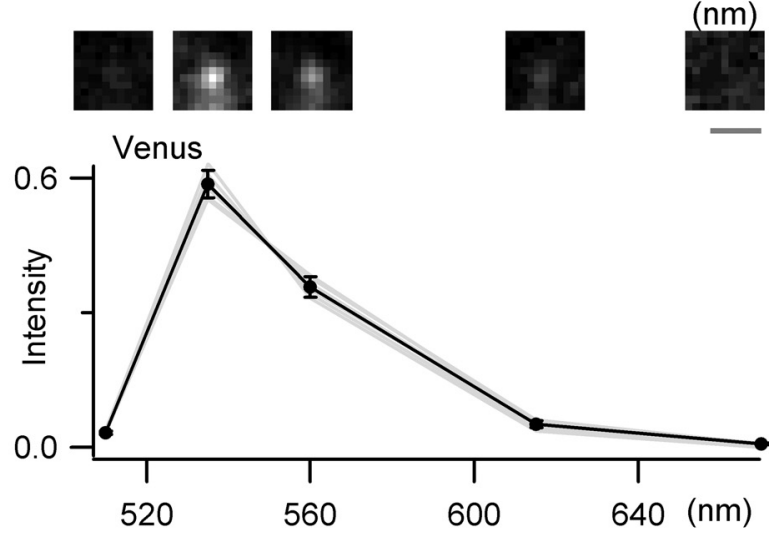

D
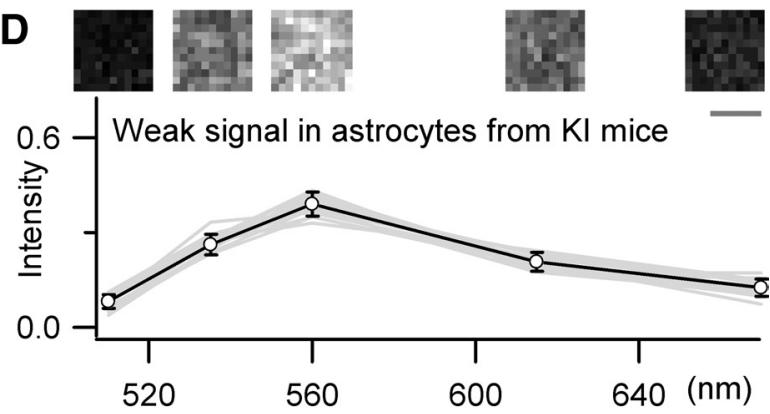

E

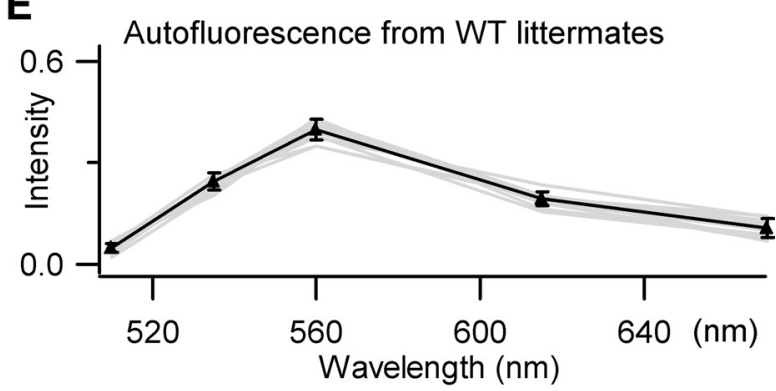

Figure 2. Cultured astrocytes from VGLUT1 ${ }^{\text {Venus }} \mathrm{KI}$ mice do not express Venus. A, Top, Autoscaled EPI images of an acute live hippocampal slice prepared from a VGLUT1 ${ }^{\text {Venus }} \mathrm{KI}$ mouse. Images were sequentially acquired using discrete narrowband emission filters (numbers indicate the filter central wavelength; details in Table 2). Stratum radiatum (SR) and stratum lucidum (SL) CA3 regions appeared more fluorescent. Bottom, Five-point spectra of VGLUT1-Venus KI CA3 ROIs measured in SR (black trace, average of eight $50 \times 50 \mu \mathrm{m} \mathrm{ROIs} \mathrm{from} \mathrm{two} \mathrm{slices;} \mathrm{the} \mathrm{black} \mathrm{circle} \mathrm{in} A$ at $535 \mathrm{~nm}$ shows one SR ROI) and in a nonfluorescent region to estimate the background (gray trace, average of six ROls; gray circle shows one background ROl). Scale bar, $100 \mu \mathrm{m}$. B, Top, Dual-color TIRFM images of a live cultured astrocyte prepared from VGLUT1 ${ }^{\text {Venus }} \mathrm{KI}$ mice and loaded with the red-fluorescent lysosomal marker FM4 - 64 (spectrally distinct from the yellow fluorescent Venus) to identify the focal plane. Inset, Cultured live astrocyte transfected with a VGLUT1-Venus-encoding plasmid expressed highly fluorescent vesicles. Scale bar, $10 \mu \mathrm{m}$. Bottom, Intensity and density of fluorescent puncta in live astrocytes from VGLUT1 ${ }^{\text {Venus }} \mathrm{KI}$ mice labeled with FM4 - 64 in dual-color TIRF images (VGLUT1-Venus and FM4-64) and in live astrocytes transfected with VGLUT1Venus (Transfection). C, Spectral profile of the yellow fluorescence measured from individual vesicles in live astrocytes transfected with VGLUT1-Venus ( $n=10$ vesicles from 2 cells). Scale bar, $1 \mu \mathrm{m}$. D, Spectral profile of weakly yellow fluorescent puncta seen in live astrocytes prepared from VGLUT1 ${ }^{\text {Venus }} \mathrm{KI}$ mice (ROI shown by white arrow in $\boldsymbol{B}, n=17 \mathrm{ROIs}$ from four cells). Scale bar, $1 \mu \mathrm{m}$. $\boldsymbol{E}$, Spectral profile of autofluorescence of live astrocytes prepared from WT littermates ( $n=14$ ROls from 4 cells).

ferent color channels and recalculated $r_{12}$ for each shifted pair. This analysis was performed in all four cardinal directions, and the obtained $r_{12}$ values averaged and plotted against the offset. Thus, if the fluorescent images of two proteins overlap, $r_{12}$ will decrease rapidly on a lengthscale characteristic of the size of the object that carries both fluorophores. Fluorophore presence in juxtaposed but distinct structures is manifest as a maximum of $r_{12}$ at a pixel value different from zero. Absence of colocalization or a low signal-to-noise ratio will appear as a negligible modulation of $r_{12}$ with pixel shift.

Image analysis and spectral unmixing. To count the density of fluorescent puncta, we first thresholded the image using a systematic $10 \%$ intensity criterion (fraction of the peak intensity after background subtraction), segmented the image with a watershed particle analyzing process using National Institutes of Health ImageJ and MetaMorph 7.0, and then counted the number of puncta/ $\mu \mathrm{m}^{2}$. Objects had to be smaller than $8 \times 8$ pixels and larger than $2 \times 2$ pixels. Their number was normalized with the total area of the ROI. For TIRF images, the contour of the cellular footprint was traced by hand and the mean fluorescence intensity within this ROI was measured.

We compared the fluorescence spectra of individual diffractionlimited puncta (putative vesicles) in astrocytes transfected with VGLUT1-Venus, and in astrocytes from the VGLUT1 ${ }^{\text {Venus }} \mathrm{KI}$ mice as well as their WT littermates, by spectral imaging and linear unmixing (Nadrigny et al., 2006, 2007). Briefly, all fluorophore spectra were determined by acquiring five discrete EPI images using narrowband emission filters (Table 2). We subtracted from the raw images the background taken from cell-free regions, and normalized the fivepoint spectra to the total fluorescence intensity (equal energy). The 
normalized five-point spectra were then compared with that of autofluorescence or cytoplasmically expressed Venus, by calculating their spectral angle $\Theta_{\lambda}$

$$
\Theta_{\lambda}=\arccos \left(\frac{\hat{\mathbf{R}}(x, y) \bullet \hat{\mathbf{S}}(x, y)}{\|\hat{\mathbf{R}}(x, y)\| \cdot\|\hat{\mathbf{S}}(x, y)\|}\right),
$$

where $\|\mathbf{x}\|=\sqrt{\sum_{i} x_{l}^{2}}$. The average spectra of two species were considered different when the spectral angle was bigger than the inner species variability of the respective vector bundles.

Statistics. All normally distributed data are expressed as mean $\pm \mathrm{SD}$, and the $t$ test was used for testing the significance of $p$ values. Non-normally distributed data were compared using their median \pm absolute deviation and nonparametric tests (KolmogorovSmirnov). All statistics used MATLAB (MathWorks). ${ }^{\star} p<0.05 ;{ }^{* *} p<0.01 ;{ }^{* *} p<$ $0.001 ;$ n.s., not significant.

\section{Results}

Evidence for VGLUT1 and VGLUT2 expression by astrocytes in culture has been provided using immunostaining (Bezzi et al., 2004; Montana et al., 2004; Zhang et al., 2004; Anlauf and Derouiche, 2005; Bowser and Khakh, 2007; Stenovec et al., 2007; Marchaland et al., 2008); however, control experiments with $\mathrm{KO}$ mice to examine the specificity of antibodies were performed in only two cases (Ormel et al., $2012 a, b)$. As a first step, we therefore systematically re-investigated VGLUT1-3 immunostaining in cultured astrocytes from WT, HZ, and KO littermates, and studied the expression of fluorescent protein by cultured astrocytes from VGLUT1 ${ }^{\text {Venus }} \mathrm{KI}$ and VGLUT2-EGFP mice.

\section{VGLUT1 expression in cultured astrocytes}

VGLUT1 is widely expressed by hippocampal and neocortical neurons (Fremeau et al., 2004a). There is also some evidence for VGLUT1 expression by cultured astrocytes (Montana et al., 2004; Zhang et al., 2004; Anlauf and Derouiche, 2005; Bowser and Khakh, 2007; Stenovec et al., 2007; Marchaland et al., 2008); however, controls using VGLUT1 KO mice have not been performed. We first tested the possible expression of VGLUT1 in astrocytes using hippocampal neuron/astrocyte cocultures and pure cultures of cortical astrocytes (Fig. 1). Experiments were performed using hippocampal neuron/astrocyte cocultures prepared from VGLUT1 HZ and $\mathrm{KO}$ mice and triple immunostaining with antibodies against VGLUT1, synapsin (a presynaptic neuronal protein), and the astrocyte-specific GFAP, respectively. As expected, the neuronal VGLUT1 labeling was lost in cultures from VGLUT1 KO mice, confirming the neuronal expression of VGLUT1. The VGLUT1 fluores(C). Scale bars: $10 \mu \mathrm{m}$.
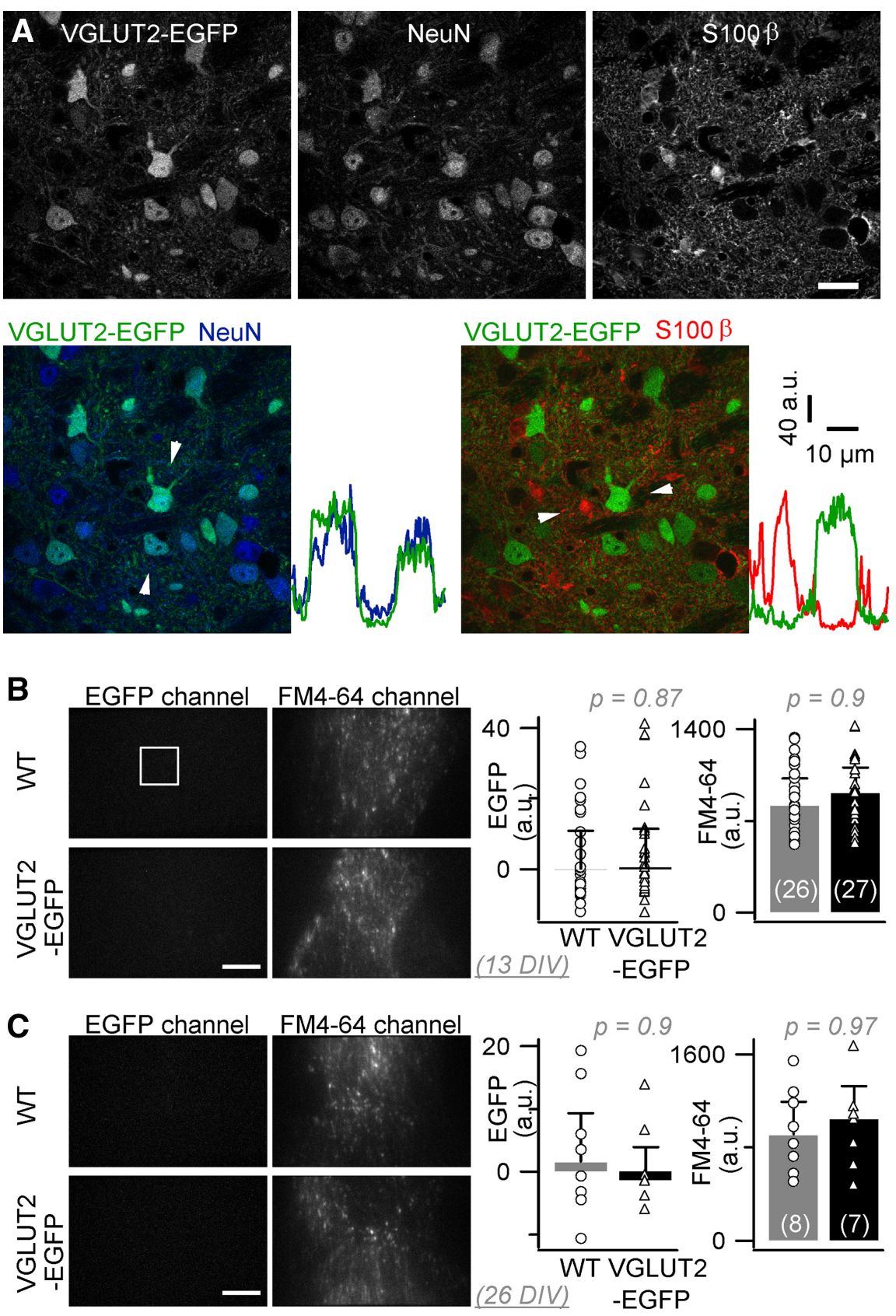

Figure 3. Astrocytes from VGLUT2-EGFP mice do not express EGFP. $A$, Top, Triple-color confocal images in thalamic VB nucleus of a VGLUT2-EGFP Tg mouse immunostained with antibodies against NeuN, S100 $\beta$, and GFP ( X63 NA1.4 oil objective). Bottom, Line profiles across somatic regions (between the arrowheads) show that cell bodies of $S 100 \beta$-positive cells, unlike NeuN-positive relay neurons, do not express EGFP. Scale bar, $20 \mu \mathrm{m}$. $\boldsymbol{B}$, Left, Dual-color TIRFM images of cultured astrocytes prepared from VGLUT2-EGFP Tg mice and their WT littermates and maintained 13 DIV. Cells were colabeled with the red-fluorescent lysosomal marker FM4 - 64. No difference in EGFP signal was found between astrocytes prepared from VGLUT2-EGFP and WT mice. Similar results were obtained when astrocytes were kept in culture for 26 DIV

cence, quantified as the VGLUT1/synapsin fluorescence ratio, was significantly reduced in neurons from VGLUT1 KO $(0.05 \pm 0.09$, $n=533$ puncta, 12 cells $)$ compared with $\mathrm{HZ}(0.25 \pm 0.1, n=766$ puncta, 9 cells; $p<0.001)$ mice. In contrast, the weak VGLUT1 fluorescence seen in GFAP-positive astrocytes, quantified as VGLUT1/GFAP fluorescence ratio, was similar in cells from VGLUT1 HZ $(0.28 \pm 0.12, n=70$ cells $)$ and $\mathrm{KO}$ mice $(0.28 \pm 0.16$, $n=87$ cells; $p=0.87)$, indicating that the fluorescence detected at the power and gain levels required to reveal VGLUT1 signal is, in 

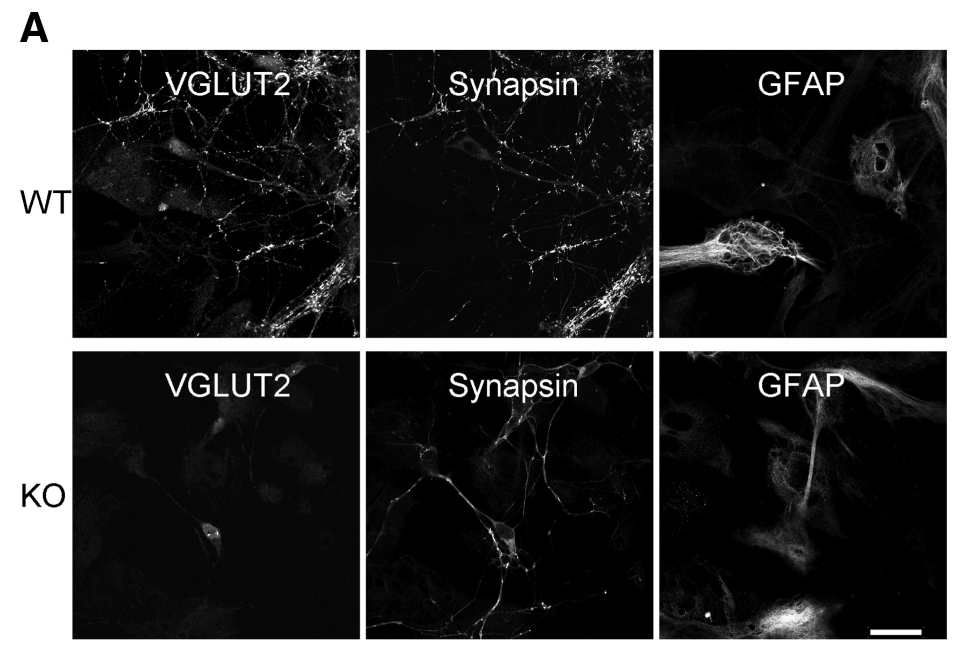

Synapsin(+) Neuron
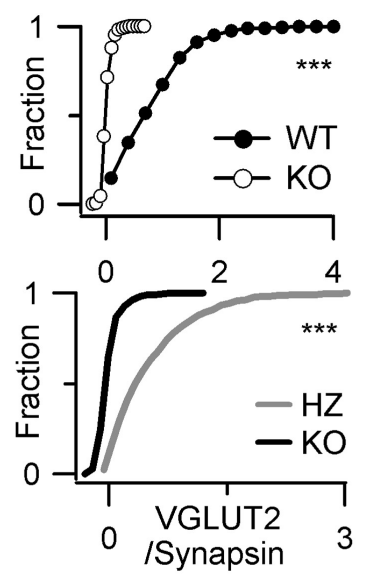
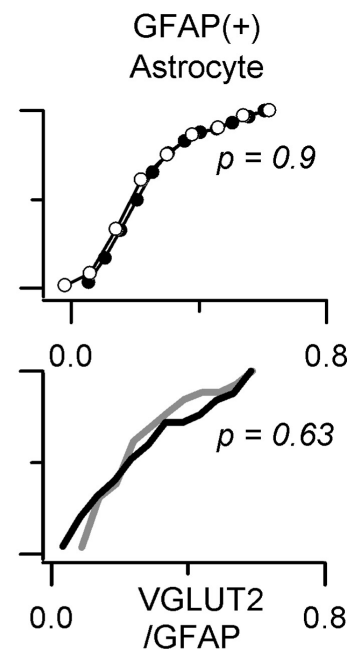
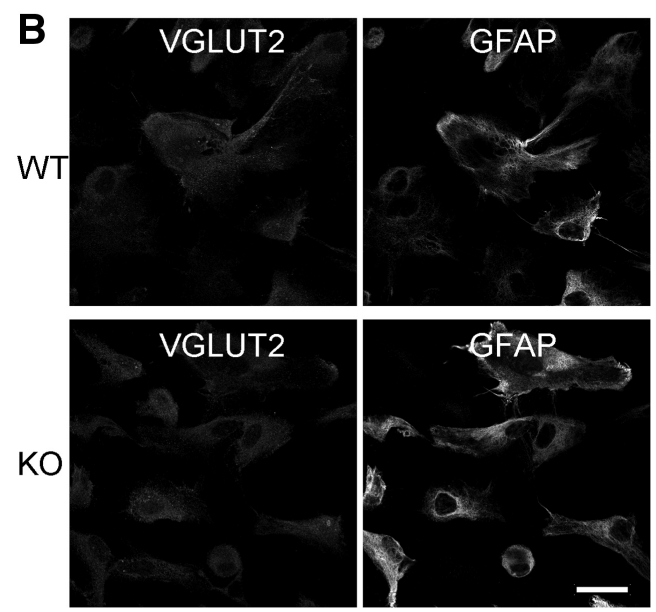

C
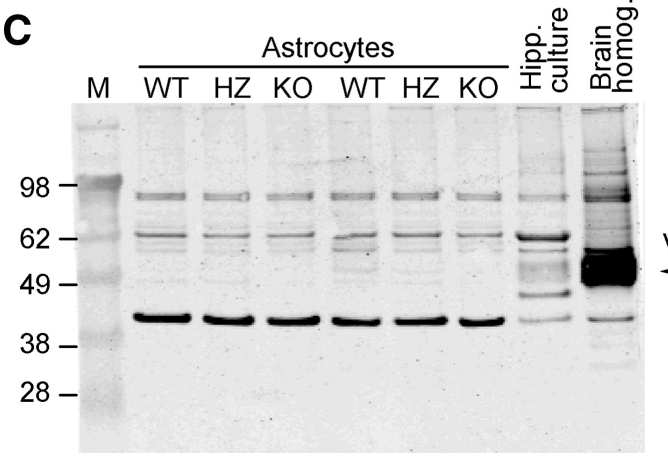
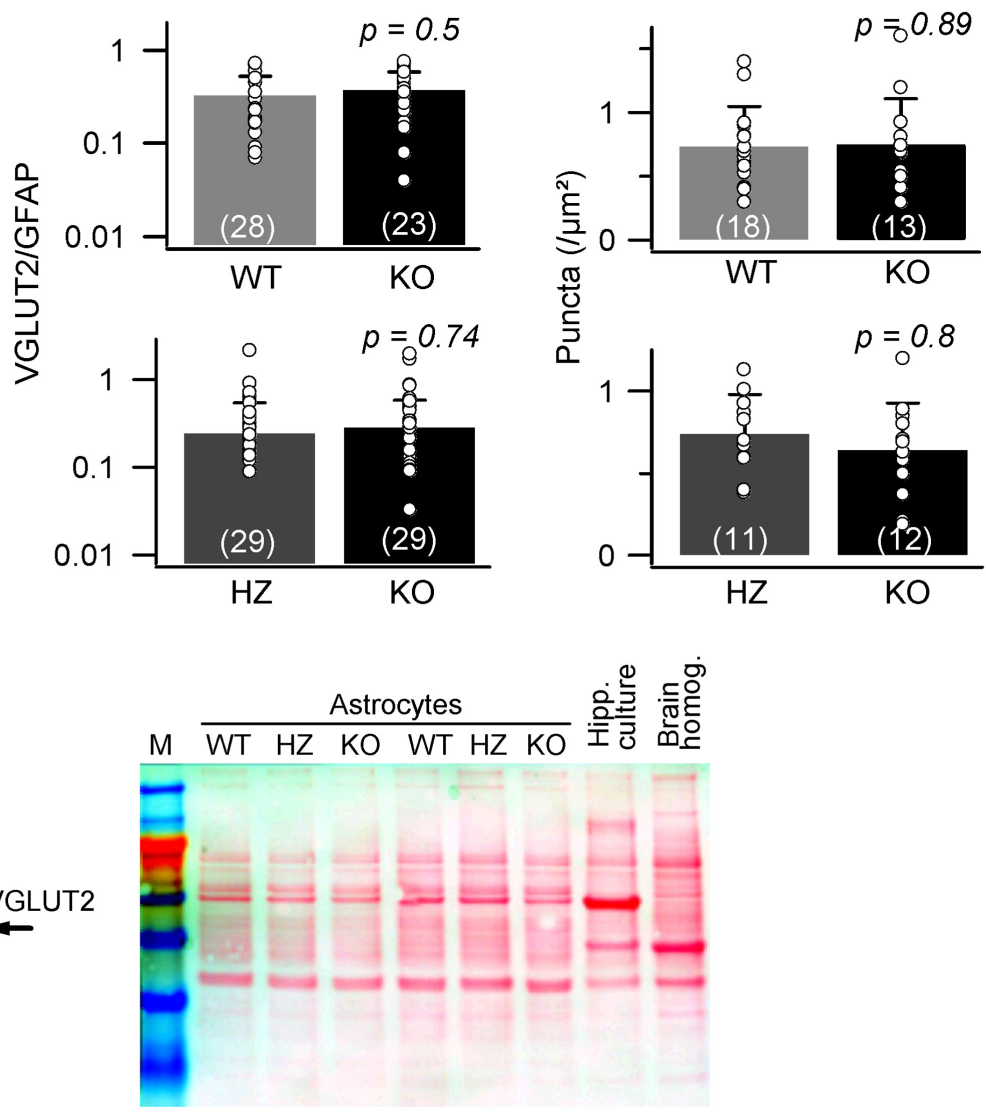

Figure 4. Astrocytes in culture do not express a specific VGLUT2 signal. $\boldsymbol{A}$, Thalamic astrocyte/neuron cocultures were prepared from VGLUT2 WT, HZ, and KO mice and immunostained with antibodies against VGLUT2, synapsin, and GFAP. The VGLUT2 immunostaining seen in synapsin-positive neurons from VGLUT2 WT ( $n=500$ synapsin-positive puncta from 6 trials) and HZ ( $n=881$ puncta from 8 trials) mice was absent in neurons from VGLUT2 K0 mice ( $n=635$ and 710 puncta, respectively; $p<0.001)$. The weak VGLUT2 signal seen in GFAP-positive astrocytes was undistinguishable in WT ( $n=58$ cells), HZ ( $n=48$ cells), and KO ( $n=72$ and 56 cells, respectively) preparations. $B$, Pure cortical astrocytic cultures were immunostained with VGLUT2 and GFAP antibodies. The VGLUT2 labeling in astrocytes, albeit detectable, shows no difference between WT, HZ, and KO mice. C, Western blot of VGLUT2 protein in pure cultured cortical astrocytes (WT, HZ, KO), pure cultured hippocampal neurons (Hipp culture), and brain homogenate (Brain-homog.) from WT animals. Left, Western blots of VGLUT2 show a strong specific labeling in WT brain homogenate, a weak signal in hippocampal neurons, and no specific signal in WT or HZ astrocytes compared with KO cells from littermates. Right, Ponceau S staining indicates a comparable amount of protein loaded in all samples. Scale bars: $20 \mu \mathrm{m}$.

fact, not specific (Fig. 1A). Cortical astrocytes in culture were also immunostained with antibodies against VGLUT1 and S100 $\beta$ (a cytosolic $\mathrm{Ca}^{2+}$ binding protein expressed by most cortical astrocytes; Vives et al., 2003). The VGLUT1 and S100 $\beta$ fluorescence intensity, the VGLUT1/S100 $\beta$ fluorescence ratio, and the density of the VGLUT1-positive puncta were undistinguishable in astrocytes from
VGLUT1 KO and HZ mice (Fig. $1 B$ ). Similar results were obtained using different secondary (Fig. 1C), primary VGLUT1 (Fig. 1D), and again swapping the secondary (Fig. $1 E$ ) antibodies. Finally, Western blots failed to detect any specific VGLUT1 band in pure cultured astrocytes from WT mice, as compared with VGLUT1 KO preparations (Fig. $1 F, G$ ). A strong band at the correct molecular weight was 
detected in the WT but not in the KO cortical homogenate (Fig. 1G,H) and a weak but clearly visible band was present in the brainstem, a structure receiving very few VGLUT1 afferents (Herzog et al., 2001). Ponceau S staining of the membrane indicates nearly equal loading of all samples. Distinct band profiles of the Ponceau S stainings reflect different protein compositions between the brain homogenates and the astrocyte cultures (Fig. $1 F-H)$. Similar results were obtained from two different antibodies (Fig. 1F; rabbit anti-VGLUT1 BN 3L2BF from Herzog et al., 2001 and Fig. 1G; guinea pig AB5905 from Millipore; see also Table 1). In addition, we observed consistent absence of VGLUT1 signal in astrocytes from WT and KO littermates kept for 10, 17, and 24 DIV (Fig. 1H). These results indicate that cultured astrocytes do not express significant levels of VGLUT1 protein.

An alternative strategy to using immunofluorescence is based on the use of fluorescent KI mice with the fluorescent Venus DNA inserted in frame before the stop codon of VGLUT1 genomic locus. Hence VGLUT1 ${ }^{\text {venus }}$ is expressed in place of the endogenous protein virtually without any alterations. As a result, Venus fluorescence is enriched in the axon synaptic terminals of the VGLUT1-positive neurons (Herzog et al., 2011). We used this mouse line as an independent assay for testing the possible VGLUT1 expression by cortical astrocytes in culture. We first confirmed in acute brain slices the presence of a strong fluorescent signal in hippocampal layers, which are enriched in VGLUT1 with a fluorescence emission peak near $528 \mathrm{~nm}$, as expected (Herzog et al., 2011) for the yellow-fluorescent Venus protein (Fig. 2A). Live-cell dualcolor TIRFM did not reveal a significant amount of Venus in cultured cortical astrocytes prepared from VGLUT1 ${ }^{\text {Venus }} \mathrm{KI}$ mice (Fig. 2B). This was not due to the limited sensitivity of our microscope or to focusing error, because individual nearmembrane lysosomes labeled with the red styryl dye FM4-64 (Zhang et al., 2007; Li et al., 2008) were reliably detected (wholecell fluorescence, $25.6 \pm 7.9$ a.u., $n=8$ cells for FM4-64 vs $1.9 \pm$ 0.9 a.u., $n=14$ cells for Venus). Likewise, astrocytes transfected with a VGLUT1-Venus plasmid expressed a high density $(0.1 \pm 0.03$ / $\mu \mathrm{m}^{2}$ ) of highly fluorescent puncta (67.4 \pm 30.2 a.u., $n=13$ cells), demonstrating our ability to detect individual Venus-positive fluorescent puncta. Furthermore, the spectral profile of individual fluorescent vesicles in the VGLUT1-Venus-transfected astrocytes (Fig. 2C) differed from that of the weakly fluorescent puncta in cultured astrocytes prepared from VGLUT1 ${ }^{\text {Venus }}$ KI mice (Fig. $2 D)$, the latter being similar to the spectral profile of autofluorescence (AF) seen in astrocytes prepared from WT mice (Fig. 2E).
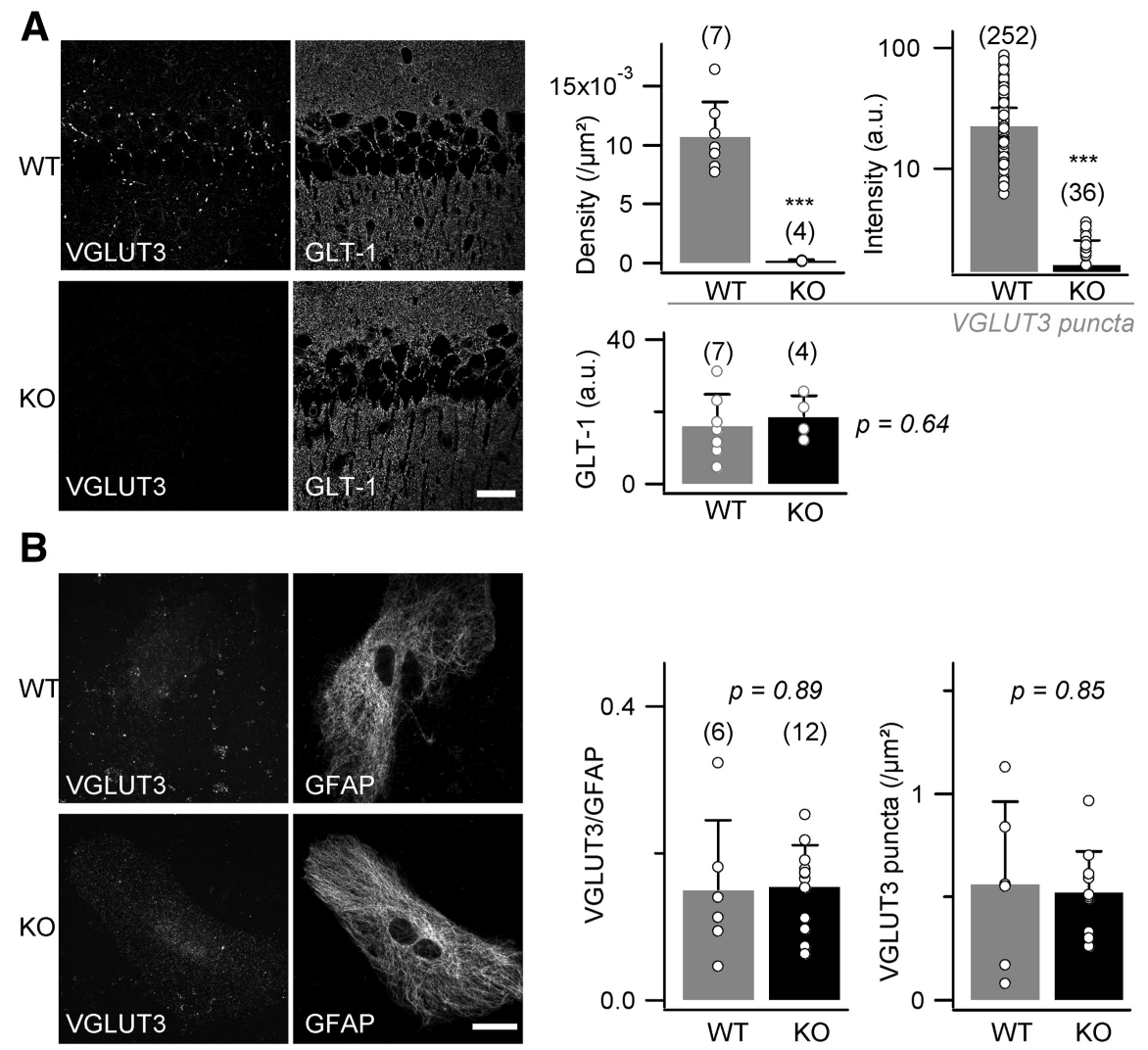

VGLUT3 puncta
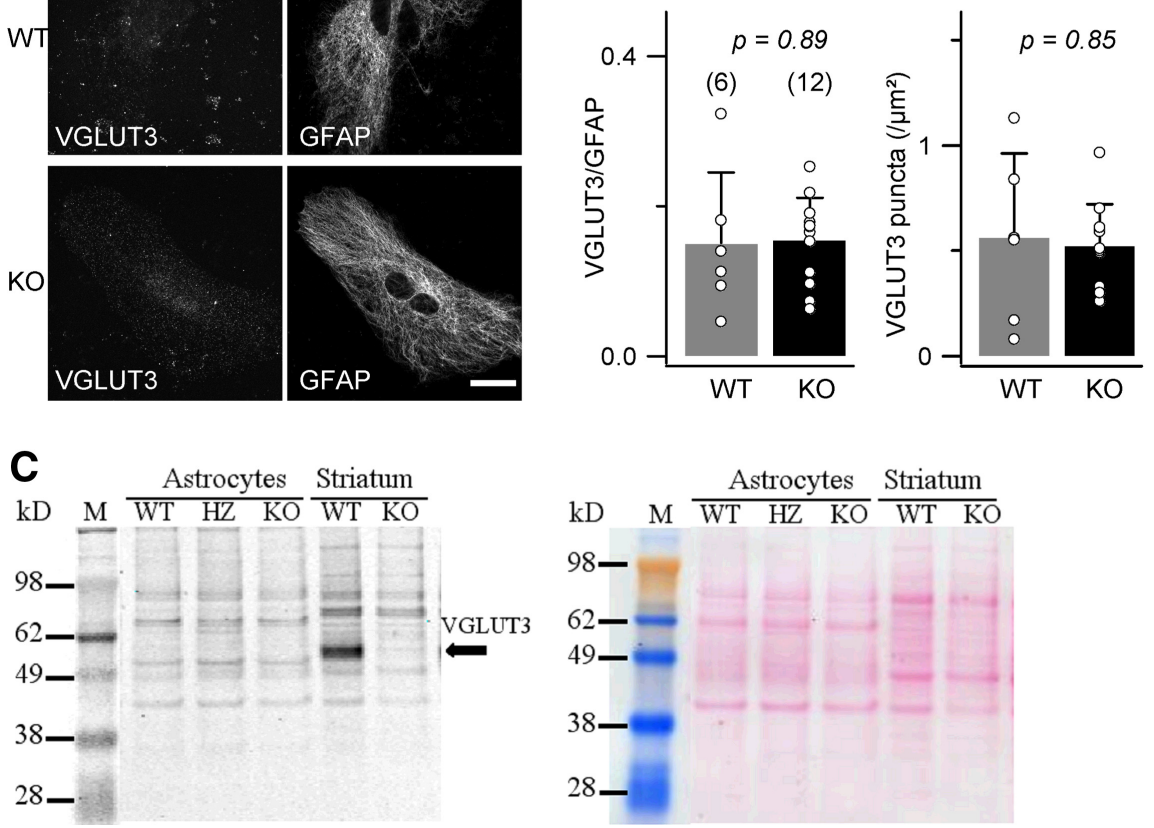

Figure 5. Astrocytes do not express a specific VGLUT3 signal. $\boldsymbol{A}$, Dual-color confocal images of CA1 hippocampal regions in the

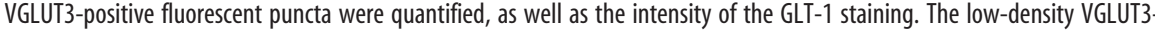
positive puncta seen in the SP and SR of WT littermates (WT) disappeared in the slices of the VGLUT3 KO mice (KO) without any change of the GLT-1 fluorescent signal. $\boldsymbol{B}$, Pure cortical astrocyte cultures from WT and VGLUT3 KO mice were coimmunostained from WT and VGLUT3 KO mice. C, Western blot analysis of cultured cortical astrocytes and striatal tissue from VGLUT3 WT, HZ, and $\mathrm{KO}$ mice. Ponceau S staining shows that an equal amount of protein was loaded in all lanes (right). A specific signal is present only in the WT striatum sample, while missing from KO striatum as well as astrocytes of all genotypes (left). Scale bars: $20 \mu \mathrm{m}$.

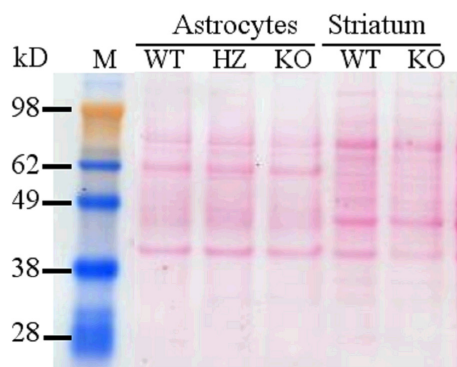

Similarity among spectral profiles was quantified using the innerspecies and interspecies variability of the spectral angle (see Materials and Methods). The innerspecies variability of the spectral angle was smaller (8.4 and $6.21^{\circ}$ for VGLUT1-Venus-transfected astrocytes, and in astrocytes prepared from VGLUT1 ${ }^{\text {Venus }} \mathrm{KI}$ mice, respectively) than the interspecies spectral angle between these two signals $\left(31.7^{\circ}\right)$, meaning that the spectral vector bundles are distinct and that the faint signal seen in the Venus channel in astrocytes prepared from VGLUT1 ${ }^{\text {Venus }} \mathrm{KI}$ mice originated from a fluorophore different from Venus. Rather, it appears to be due to AF as evidenced by the small interspecies variability of the spectral angle between the faint Venus and AF signals, which is $4.01^{\circ}$, a value smaller than the innerspecies variability of AF spec- 
A $S 100 B$
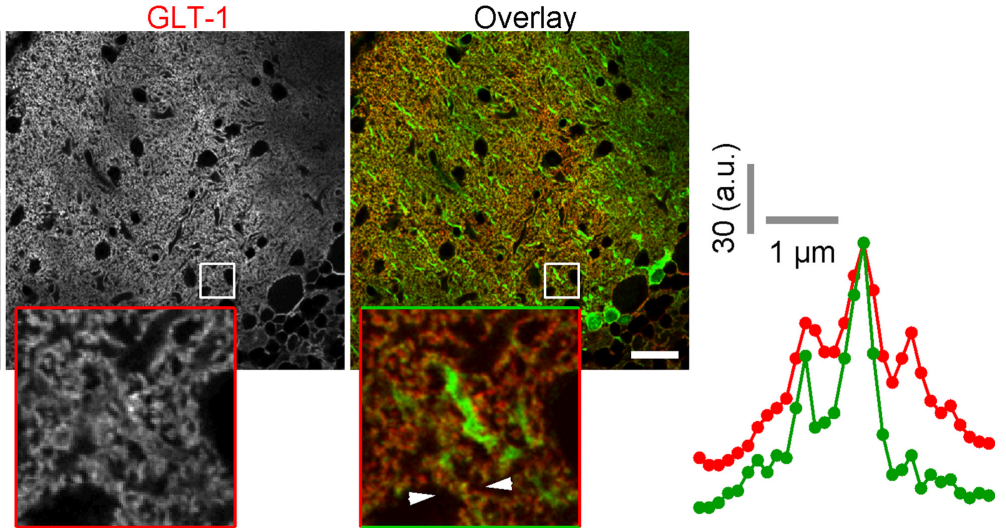

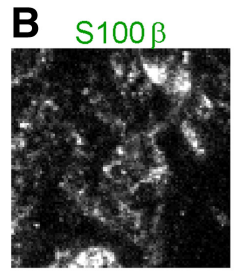

GLT-1
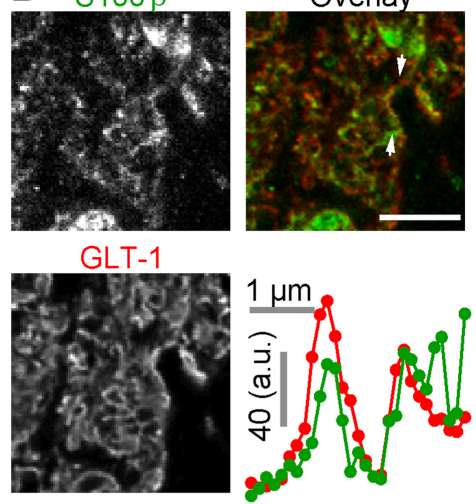

D
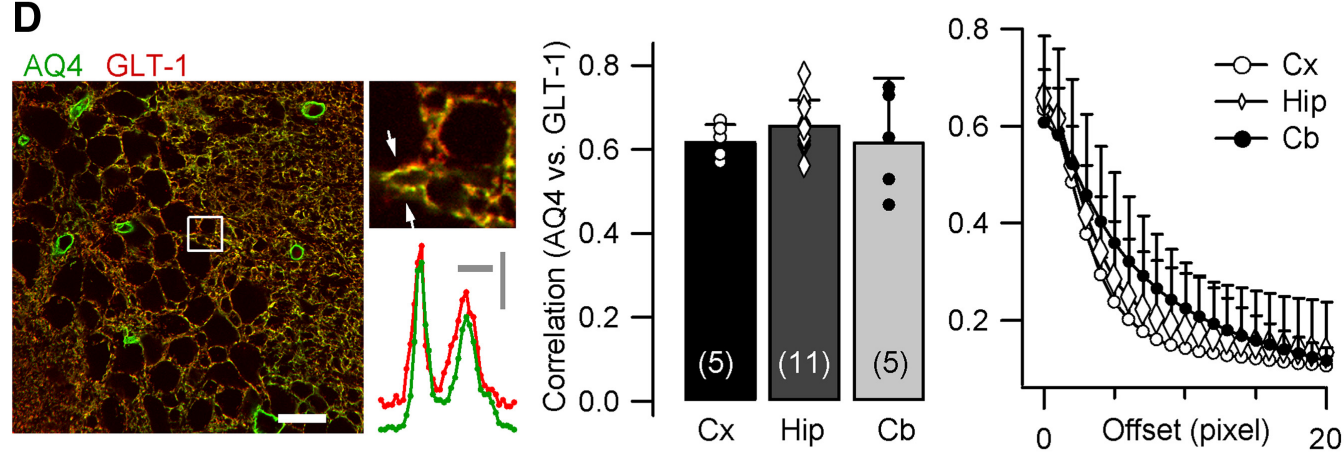

E

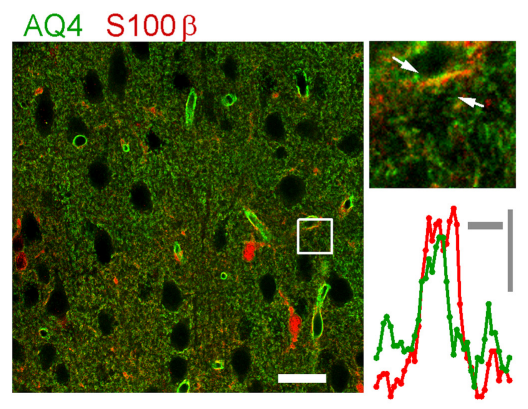

C

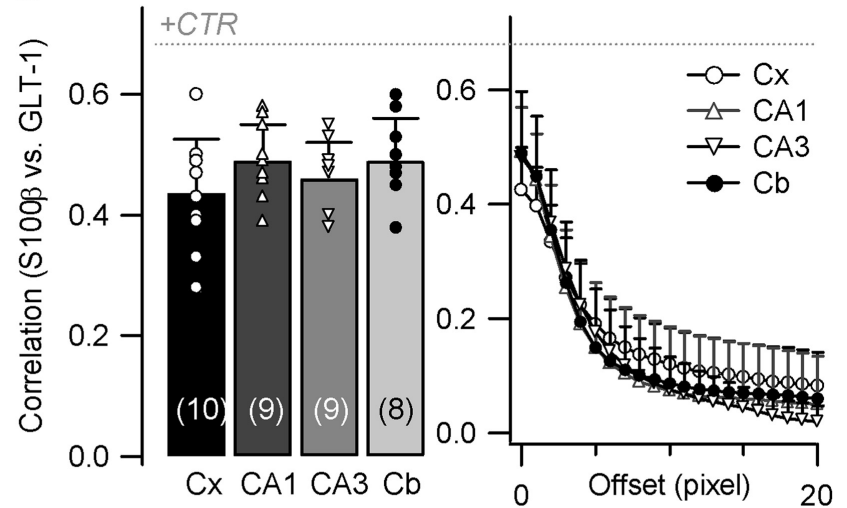


A
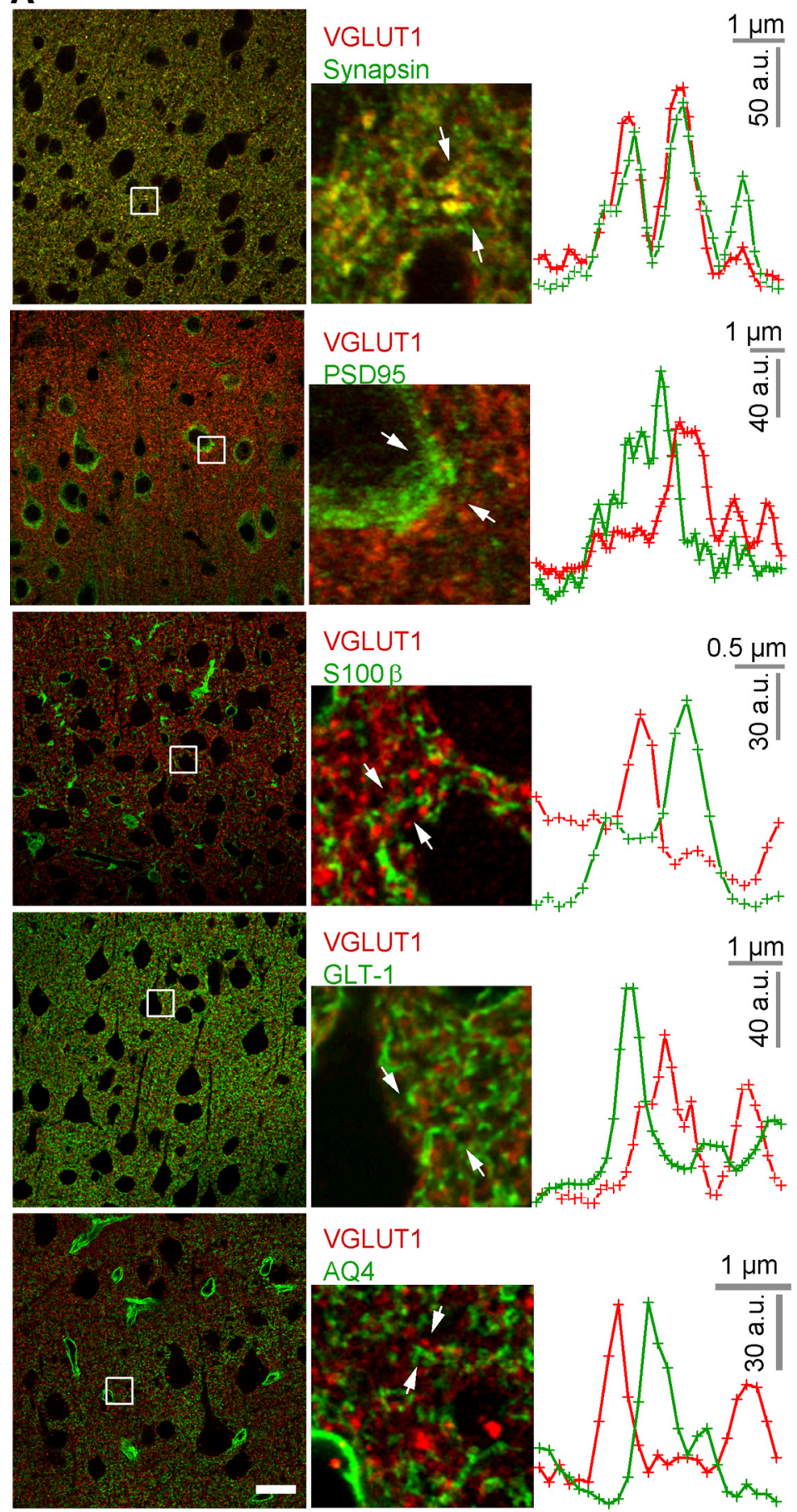

C $0.8-(19)$

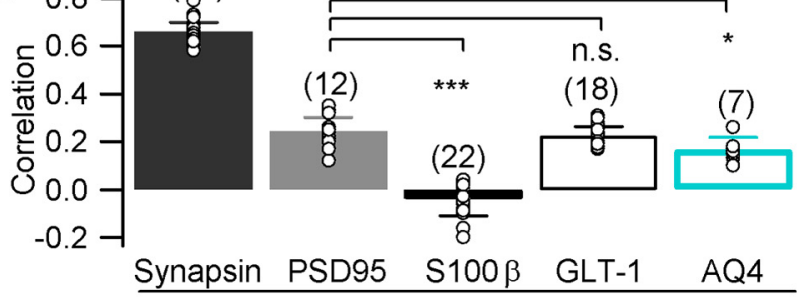

vS. VGLUT1
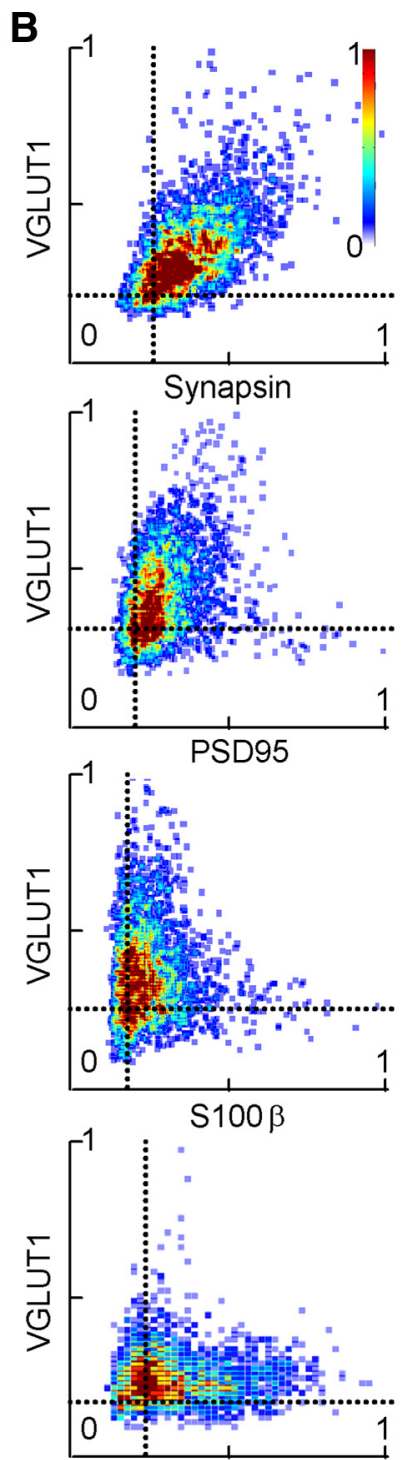

GLT-1

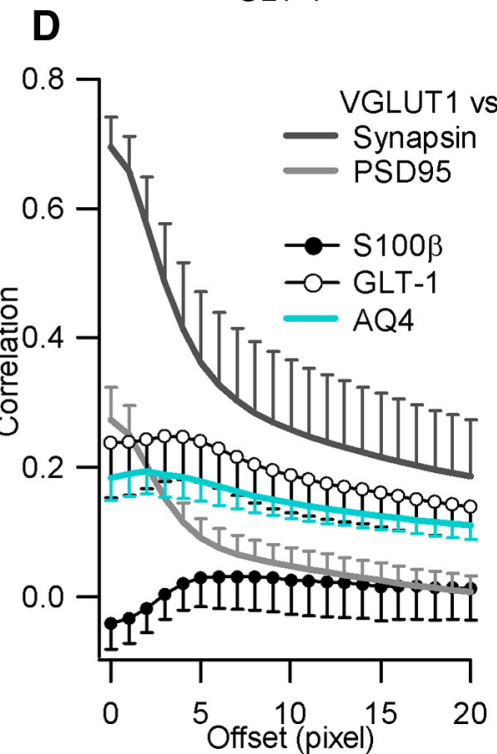

Figure 7. VGLUT1 and astrocytic markers do not colocalize in the somatosensory S1 cortex. $\boldsymbol{A}$, Left, High-magnification ( $\times 63 / \mathrm{NA} 1.4$ oil objective) confocal images of S1 cortical slices immunostained with antibodies against VGLUT1; synapsin as a positive control; PSD-95 as a negative control; and astrocytic markers S100 $\beta$, GLT-1, and AQ4. Middle, Magnified R0Is indicated by a white square on the left side. Right, Fluorescence intensity line profiles between the white arrows shown in the magnified subregions. Scale bar, $20 \mu \mathrm{m}$. $\boldsymbol{B}$, (Figure legend continues.) 
tra, which was $6.63^{\circ}$. In line with the immunofluorescence data, our results indicate that cortical astrocytes cultured from VGLUT1 ${ }^{\text {Venus }}$ KI mice do not express detectable amounts of the VGLUT1 protein.

\section{VGLUT2 expression in cultured astrocytes}

VGLUT1 and VGLUT2 are both expressed by glutamatergic neurons; however, they are found in different subtypes of neurons (Bai et al., 2001; Fremeau et al., 2001; Herzog et al., 2001; SakataHaga et al., 2001; Takamori et al., 2001), VGLUT1 being expressed by most cortical neurons, and VGLUT2 by the thalamocortical relay neurons (Fremeau et al., 2004b; Nakamura et al., 2005). Previous studies found VGLUT2 expression in cultured astrocytes (Montana et al., 2004; Anlauf and Derouiche, 2005; Crippa et al., 2006; Ni and Parpura, 2009); however, control experiments using VGLUT2 KO mice are missing. We therefore investigated the possible expression of VGLUT2 by cultured astrocytes prepared from VGLUT2-EGFP Tg mice, VGLUT2 KO mice, and their WT/HZ/KO littermates.

Unlike in the VGLUT1 ${ }^{\text {Venus }}$ KI mice used above, EGFP is not targeted to VGLUT2-expressing vesicles in VGLUT2-EGFP Tg mice and it labels the cytosol of VGLUT2-expressing cells. In fixed thalamic slices, cell bodies of NeuN-positive ventrobasal (VB) neurons were labeled with EGFP (Fig. 3A), as expected for VGLUT2-expressing relay neurons (Fremeau et al., 2004b; Nakamura et al., 2005). Interestingly, in the same slices, the cell bodies of $S 100 \beta$-positive astrocytes lacked detectable amounts of EGFP. Next, to examine a possible glial expression of VGLUT2 in culture, astrocytes from VGLUT2-EGFP HZ and WT littermates were maintained 13 and 26 DIV. Using live-cell dual-color EGFP and FM4-64 TIRF imaging (Li et al., 2008), we found no significant difference in the EGFP signal between the two types of astrocyte preparations, neither at $13 \mathrm{DIV}$ (Fig. $3 B$ ) nor at $26 \mathrm{DIV}$ (Fig. 3C), suggesting that cultured cortical astrocytes do not express VGLUT2.

Second, we compared VGLUT2 expression in VGLUT2 WT, $\mathrm{HZ}$, and KO mice using neuron/astrocyte cocultures (Fig. 4A), pure astrocytic cultures (Fig. 4B), and Western blots (Fig. 4C). Since VGLUT2 is expressed by thalamic relay neurons, neuron/ astrocyte cocultures were prepared from the thalamus and maintained 15 DIV before fixation and triple-color immunostaining using antibodies against VGLUT2, GFAP to identify astrocytes (Nolte et al., 2001), and synapsin to visualize synaptic terminals (Fig. 4A). The VGLUT2 fluorescence intensity was normalized to synapsin or GFAP fluorescence to compare among images and samples. As expected, the VGLUT2/synapsin ratios were significantly different in cocultures from VGLUT2 WT/HZ and KO

\footnotetext{
(Figure legend continued.) Examples of density-coded scatter plots for subregions of several pairs of labeling. The position of the data points depends on the normalized relative intensity of corresponding pixels from image pairs displayed in one dimension along the $x$ - and $y$-axis. Dashed lines indicate the intensity of the background plus three times its SD; the top right quadrant contains the "red" and "green" pixels that are significantly different from background. Only the data points exceeding the dashed lines were used for calculating the Pearson's correlation coefficient, $r_{12}$. The density of the data points is color encoded and shows the heterogeneous distribution of pixel-intensity ratios. C, The colocalization between VGLUT1 and several markers was quantified by the Pearson's correlation coefficient $r_{12}(n=3$ mice for synapsin; $n=2$ for PSD- $95 ; n=4$ for S100 $\beta ; n=3$ for GLT-1; $n=1$ for AQ4). The number of regions analyzed is given on the top of each bar. D, Pearson's $r_{12}$ values against the pixel offset shows an immediate decrease with pixel shift for VGLUT1/synapsin and VGLUT1/PSD-95, which contrasts with the slight increase seen for VGLUT1/S100 $\beta$, and a delayed and small shift for VGLUT1/ GLT-1 and VGLUT1/AQ4 $(n=7)$.
}

mice, confirming the neuronal expression of the VGLUT2. In contrast, we found no significant difference in VGLUT2/GFAP ratios between neuron/astrocyte cocultures and between pure astrocytic cultures from VGLUT2 WT, HZ, and KO mice. Likewise, the densities of fluorescent puncta detected with VGLUT2 immunolabeling were similar in pure astrocytic cultures from VGLUT2 WT, HZ, and KO mice (Fig. 4B). Finally, the faint signal seen in the Western blots from cultured astrocytes was similar in the VGLUT2 WT, HZ, and KO preparations, whereas a strong specific band was present in the whole brain homogenate and a weak but clearly visible signal appeared in the cultured hippocampal neurons (DIV 18; Fig. 4C), which express very low levels of VGLUT2 (Wojcik et al., 2004). These results indicate a lack of specific VGLUT2 labeling in cultured astrocytes.

\section{VGLUT3 expression in cultured astrocytes}

Unlike VGLUT1 and VGLUT2, which are expressed by glutamatergic neurons, VGLUT3 is found in GABAergic, cholinergic, and monoaminergic neurons (Fremeau et al., 2002; Gras et al., 2002; Schäfer et al., 2002). There is also some indication that astrocytes in situ express VGLUT3 (Fremeau et al., 2002), but again, this expression remains to be confirmed by appropriate controls with $\mathrm{KO}$ mice.

We first compared VGLUT3 immunostaining in hippocampal slices from VGLUT3 KO mice and WT littermates (Fig. 5A). After fixation, the slices were double labeled with antibodies against VGLUT3 and the plasma membrane type-1 glutamate transporter (GLT-1) (Chaudhry et al., 1995). VGLUT3-positive puncta seen in stratum pyramidale (SP), stratum radiatum (SR), and stratum oriens of the CA1 region in WT mice, which correspond probably to axon terminals of cholecystokinin-positive GABAergic interneurons (Somogyi et al., 2004), were not detected in the VGLUT3 KO mice, confirming the specificity of the VGLUT3 signal. Second, we compared the expression of VGLUT3 in cultured cortical astrocytes from VGLUT3 KO and WT littermates (Fig. 5B). Astrocytes were double-immunostained with antibodies against VGLUT3 and GFAP for normalization. The VGLUT3/GFAP ratio and the density of VGLUT3-positive puncta were similar in VGLUT3 KO and WT mice, indicating that the VGLUT3 signal in cultured astrocytes is unspecific. Third, Western blots of cultured cortical astrocytes from VGLUT3 WT, HZ, and KO littermates showed no specific VGLUT3 band at the correct molecular weight similar to the band seen in the striatum homogenate from VGLUT3 WT, which disappeared in $\mathrm{KO}$ striatal samples (Fig. 5C). The VGLUT3 protein produces a higher background signal than the other two VGLUT antibodies, but none of the additional bands disappear in the KO samples. Thus, taken together, our results indicate that also for VGLUT3, the weak signal seen in cultured astrocytes is due to nonspecific labeling.

\section{VGLUT1 expression in brain slices}

Since astrocytes in culture differ from their in situ counterparts (Cahoy et al., 2008), we further investigated the expression of all three VGLUT proteins in brain slices. We used double or triple immunostaining with specific antibodies against neuronal and astrocytic proteins, together with confocal microscopy, and quantitative colocalization methods in adult (P55-P65) WT and Tg mice. Confocal images were taken in the primary somatosensory (S1), hippocampal, and cerebellar cortex as well as in the thalamic ventrobasal (VB) and reticularis nuclei.

As expected (Fremeau et al., 2001; Herzog et al., 2001; Varoqui et al., 2002; Hioki et al., 2003; Boulland et al., 2004; Fremeau et al., 2004a; Nakamura et al., 2005; Graziano et al., 2008), VGLUT1 

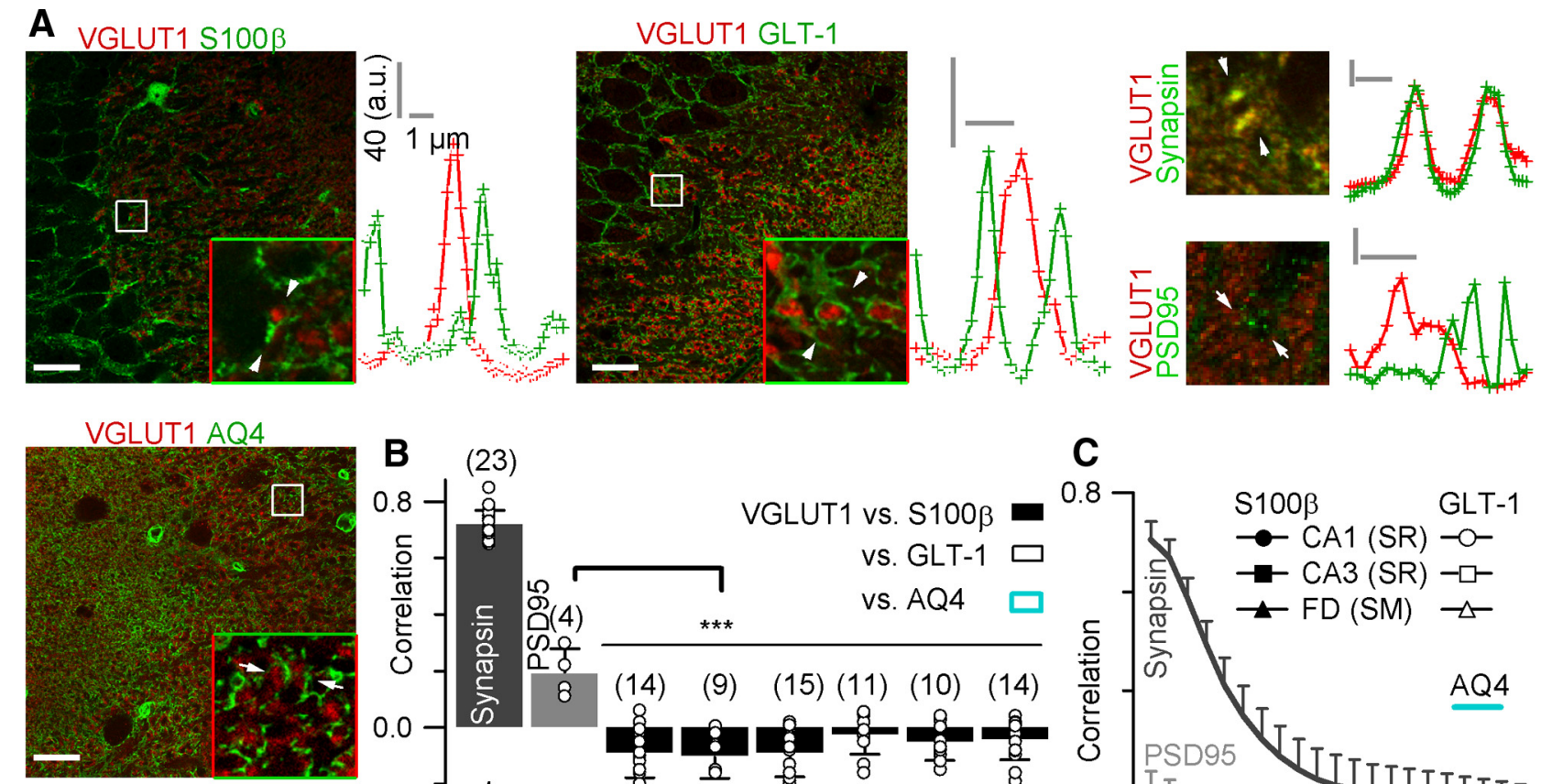

B (23)
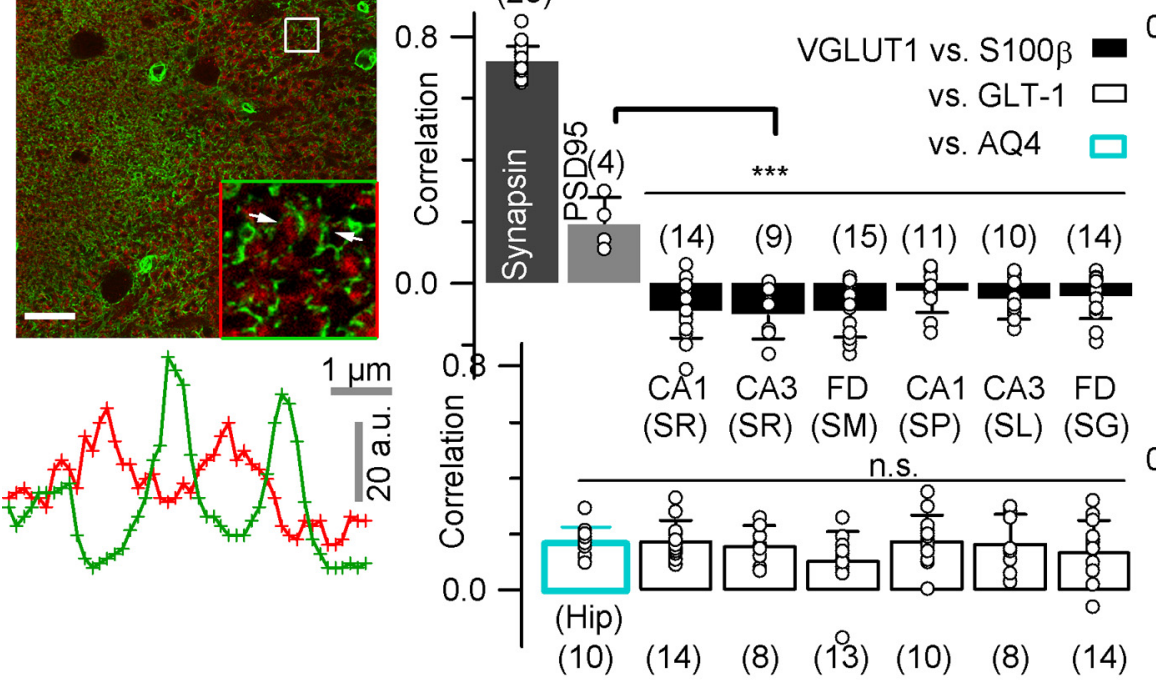

C
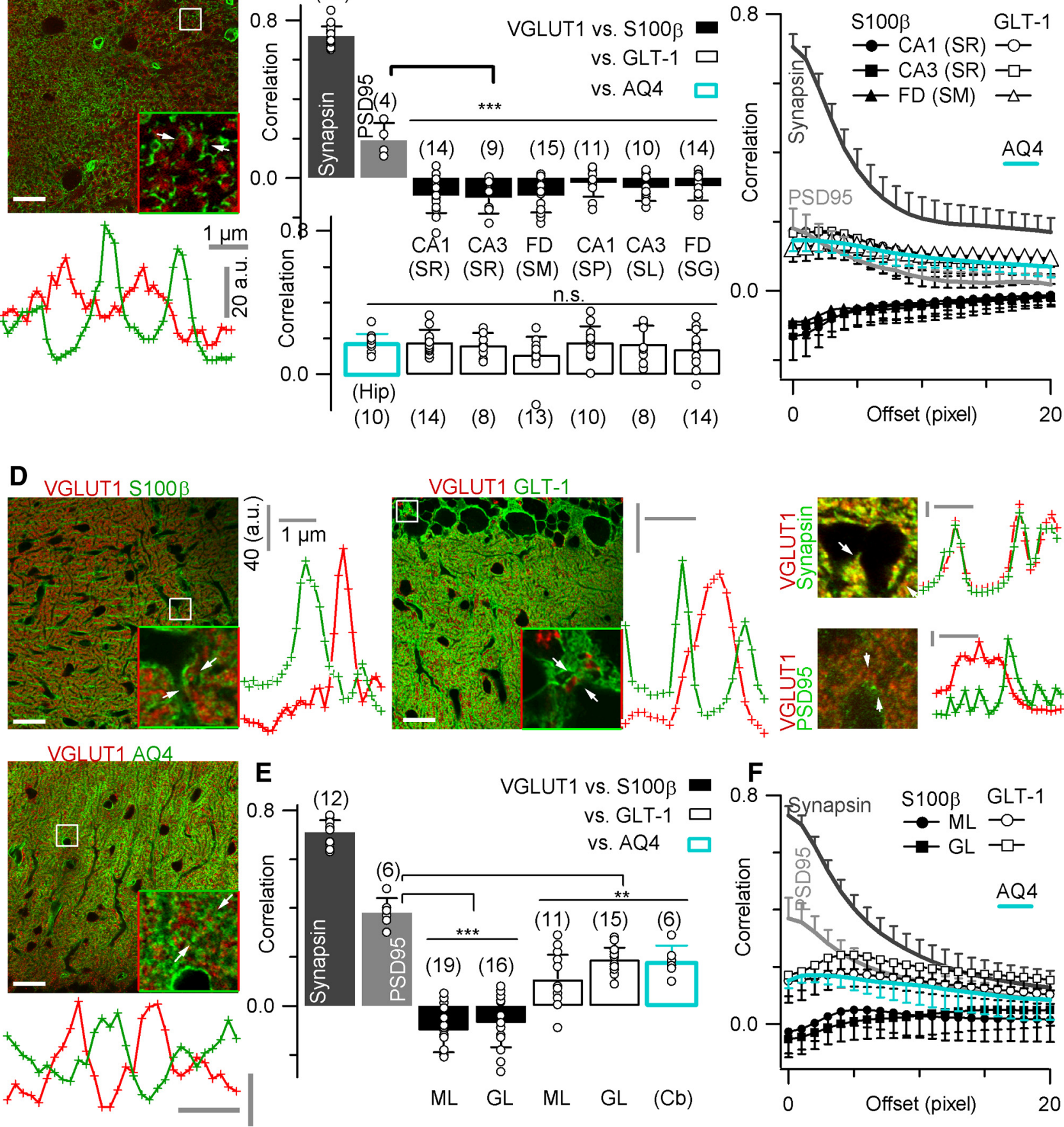

Figure 8. VGLUT1 and astrocytic markers do not colocalize in hippocampus and cerebellum. $A$, Dual-color high-magnification ( $\times 63 /$ NA 1.4 oil objective) confocal fluorescent images in hippocampus. The line profiles between the arrows in the magnified ROI $(14 \times 14 \mu \mathrm{m})$ show no overlap between VGLUT1 and PSD-95, S100 $\beta$, GLT-1, and AQ4 in CA3. This (Figure legend continues.) 
immunostaining and low-magnification $(\times 10)$ confocal imaging confirmed a high level of VGLUT1 expression in the neuropil of the neocortex, and in hippocampal and cerebellar regions of adult mice (data not shown). An earlier study using immunostaining and electron microscopy suggested that VGLUT1 is expressed by thin astrocytic processes in hippocampus (Bezzi et al., 2004). However, recent experiments using VGLUT1 KO mice indicate that a residual postembedding immunogold labeling was still present in hippocampal astrocytic processes $(\sim 60 \%)$ and synaptic terminals ( $45 \%$ ) (Ormel et al., 2012b), suggesting nonspecific labeling. Therefore, we studied the possible expression of VGLUT1 by astrocytes in S1 cortex (Fig. 7), as well as in hippocampal and cerebellar areas (see Fig. 8) using dual-color confocal imaging.

Comparing the distribution of the synaptic and astrocytic glutamatergic markers at the tripartite synapse is technically challenging because the astrocytes extend thin processes near the excitatory synapses (Ventura and Harris, 1999; Genoud et al., 2006), and the distance between synaptic and astrocytic compartments is close to or even below the spatial resolution of the confocal microscope $(\sim 150 \mathrm{~nm}$ with a $\times 63 / \mathrm{NA} 1.4$ objective at 550 $\mathrm{nm}$ ). To compare the colocalization between VGLUT1 and astrocytic or neuronal markers, we used standardized fluorophore pairs (Table 2), calculated the Pearson's correlation coefficient $\left(r_{12}\right)$, and examined the effect of an artificially introduced pixel shift between the two component images (see Materials and Methods).

To assess our ability to reliably detect colocalization, controls were performed for three astrocytic markers, S100 $\beta$, GLT-1, and the water-permeable channel aquaporin 4 (AQ4) (Fig. 6). Similar intensity line profiles and Pearson's correlation coefficient were obtained when comparing the distribution of the cytosolic marker, $S 100 \beta$, and the membrane marker, GLT-1, in the neuropil of S1 cortex, CA1/CA3 hippocampal regions, and cerebellum (Fig. $6 A-C$ ). The correlation obtained for S100 $\beta /$ GLT-1 was slightly smaller than that of VGLUT1/synapsin (+CTR) calculated in the same regions (Figs. $6 \mathrm{C}, 7$ ), probably because of the plasma membrane (GLT-1) versus cytoplasmic (S100 $\beta$ ) distribution of these glial proteins. To validate this hypothesis, we performed a colocalization experiment between GLT-1, S100 $\beta$, and AQ4, another astrocyte-specific membrane marker mostly found at the glial endfeet but also present at the tripartite synapse (Nielsen et al., 1997; Binder et al., 2012). As expected, the correlation level between the membrane markers GLT-1 and AQ4 (Fig. $6 D)$ was significantly higher than that of S100 $\beta /$ GLT-1 $(p<0.01$;

\section{$\leftarrow$}

(Figure legend continued.) contrasts with the overlapping line profiles of VGLUT1 and synapsin as shown here in the fascia dentate region. Scale bar, $20 \mu \mathrm{m}$. B, Colocalization quantification by Pearson's correlation coefficient $r_{12}$ values between VGLUT1 and different markers in hippocampal regions. Three mice were used in each condition, except for VGLUT1/GLT-1 analysis in CA3 ( $n=2$ mice), VGLUT1/PSD-95 ( $n=1$ mouse), and VGLUT1/AQ4 ( $n=1$ mouse). There is no significant difference between VGLUT1/PSD-95 and VGLUT1/GLT- $1 r_{12}$ values (n.s., $p>0.16)$. C, Effect of pixel shift on the $r_{12}$ values between VGLUT1 and different markers. Data between VGLUT1 and synapsin, PSD-95, and AQ4 $(n=10)$ are pooled for hippocampus. $\boldsymbol{D}$, High-magnification confocal images of the cerebellum and magnified ROls $(14 \times 14 \mu \mathrm{m})$. Scale bars: $20 \mu \mathrm{m}$. The fluorescence line profiles showed no correlation between VGLUT1 and the astrocytic markers $S 100 \beta$, GLT-1, and AQ4. E, Pearson's $r_{12}$ values in cerebellar ML and GL. Four mice were used for VGLUT1/S100 $\beta$ analysis, three for VGLUT1/synpasin and VGLUT1/ GLT-1, and one for VGLUT1/PSD-95. In cerebellum, the $r_{12}$ values between VGLUT1 and astrocytic markers appear significantly smaller than the VGLUT1/PSD-95-negative control value. $\boldsymbol{F}$, The effect of pixel shift on the $r_{12}$ values confirms the lack of colocalization between VGLUT1 and the astrocytic markers, S100 $\beta, \mathrm{GLT}-1$, and AQ4 ( $n=6$, pooled value from ML and GL regions).
Fig. $6 C$ ) or $\mathrm{S} 100 \beta / \mathrm{AQ} 4(p<0.01$; Fig. $6 E)$. The true colocalization between astrocytic markers was confirmed by a sharp decrease in Pearson's coefficient between S100 $\beta$ /GLT-1 (50\% over $473.4 \pm 77.2 \mathrm{~nm}$; Fig. $6 C$ ), AQ4/GLT-1 (50\% over $593.1 \pm 131.5$ nm; Fig. $6 D$ ), and S100 $\beta /$ AQ4 $(50 \%$ over $532.7 \pm 96.3 \mathrm{~nm}$; Fig. $6 E$ ) induced by pixel shift. These controls validate our ability to demonstrate the colocalization of proteins inside submicrometric astrocytic processes using dual-color confocal images.

We then compared the distribution of VGLUT1 with that of two neuronal markers (synapsin, and PSD-95), and three astrocytic markers (S100 $\beta$, GLT-1, and AQ4) in the neuropil of S1 cortex (Fig. 7), hippocampal region (Fig. $8 A-C$ ), and cerebellum (Fig. $8 D-F$ ). We first analyzed the VGLUT1/synapsin and VGLUT1/PSD-95 line profiles, density-coded scatter plots, and Pearson's correlation coefficient and its evolution when introducing a pixel shift. Whereas VGLUT1 and synapsin line profiles showed substantial overlap as expected for two presynaptic proteins, VGLUT1 and PSD-95 had slightly shifted profiles, compatible with their expression in two adjacent but different compartments (Fig. 7A). For the same reasons, the densitycoded scatter plots were symmetrical (along the $45^{\circ}$ line of strong colocalization) for VGLUT1/synapsin, but asymmetrical for VGLUT1/PSD-95 (Fig. 7B). Finally, Pearson's correlation coefficient was significantly higher for VGLUT1/synapsin than for VGLUT1/PSD-95 $\left(r_{12}=0.66 \pm 0.04, n=19\right.$ vs $0.24 \pm 0.06, n=$ 12, respectively; $p<0.0001$; Fig. $7 C$ ), and, in both cases, $r_{12}$ quickly dwindled when introducing a pixel shift as expected for synaptic proteins, which belong to subcellular compartments that are tightly associated within a diffraction-limited volume (Fig. $7 D)$. This second set of control experiments indicates that our analysis can discriminate the VGLUT1 spatial correlation with a presynaptic marker, from its correlation with a postsynaptic marker.

We next compared the distribution of the astrocyte proteins, S100 $\beta$, GLT-1, and AQ4, against VGLUT1. For all three VGLUT1 versus astrocyte marker combinations, the line profiles indicated that the labeled astrocyte processes are close by but show little overlap with VGLUT1 (Fig. 7A). Second, the density-coded scatter plots showed less correlation between VGLUT1 and astrocytic markers than between VGLUT1 and synapsin or even PSD-95 (Fig. 7B). Third, the VGLUT1/S100 $\beta$ correlation coefficient was close to zero and significantly lower than that of VGLUT1/ PSD-95 $\left(r_{12}=-0.04 \pm 0.07 n=22\right.$ vs $0.24 \pm 0.06, n=12 ; p<$ 0.001 ; Fig. $7 C$ ). Unlike the $r_{12}$ values for VGLUT1/synapsin and VGLUT1/PSD-95 that both rapidly decreased upon pixel shift, the VGLUT1/S100 $\beta$ coefficient instead showed a slight increase (Fig. $7 D$ ), indicating that $S 100 \beta$-positive astrocytic compartments are juxtaposed to synapses, but not identical with the VGLUT1 expressing compartments. We also found that the VGLUT1/GLT-1 $(0.23 \pm 0.04, n=18)$ and VGLUT1/AQ4 $(0.17 \pm 0.05, n=7) r_{12}$ value failed to exceed that for VGLUT1/ PSD-95 (0.24 $\pm 0.06, n=12$; Fig. $7 C)$, and the pixel shift did not produce a rapid falloff of the $r_{12}$ value of VGLUT1/GLT-1 and VGLUT1/AQ4 as in the case of VGLUT1/synapsin or VGLUT1/ PSD-95 (Fig. 7D). These results, like the VGLUT1/S100 $\beta$ data, again suggest that GLT-1- and AQ4-positive astrocytic processes do not overlap with but are juxtaposed to VGLUT1-expressing cellular compartments. The different evolution of $r_{12}$ with pixel shift points to different geometric arrangements with a partial and variable ensheathment of synapses by astroglial processes, and a stereotyped apposition of the presynaptic boutons and postsynaptic spines.

Using the same comparative analysis with line profiles and Pearson's correlation coefficient, quantitatively similar results 

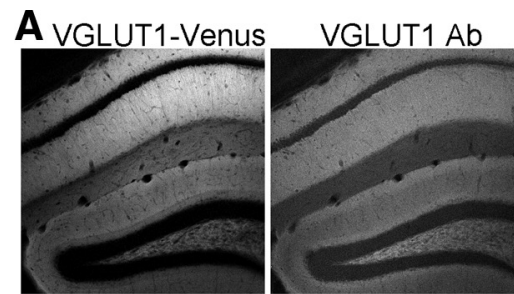

VGLUT1-Venus
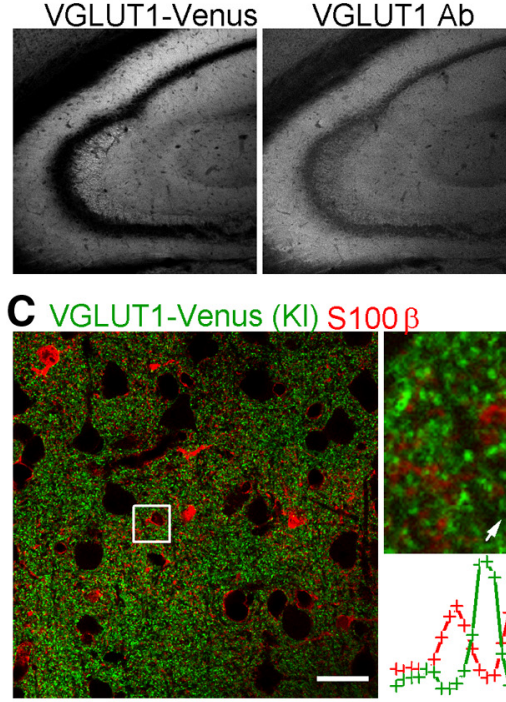

D

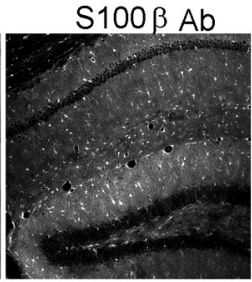

GLT-1 Ab

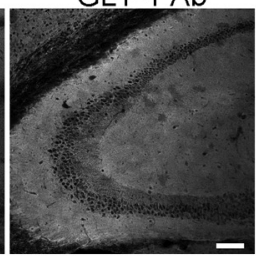

B

VGLUT1-Venus (KI) vs. VGLUT1
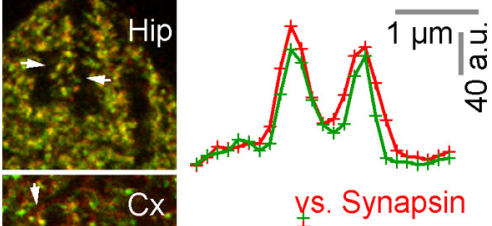

ys. Synapsin
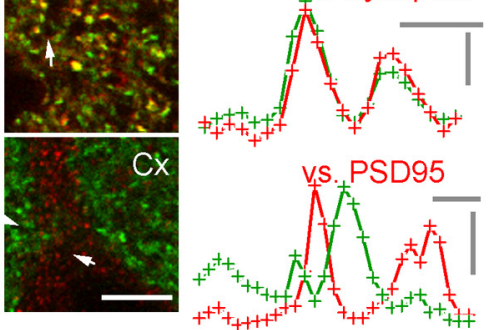

VGLUT1-Venus (KI) GLT-

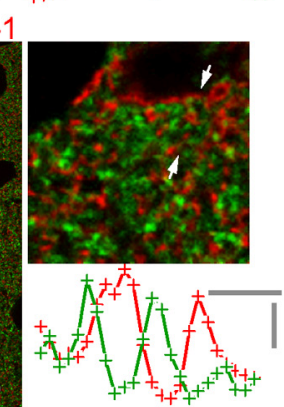

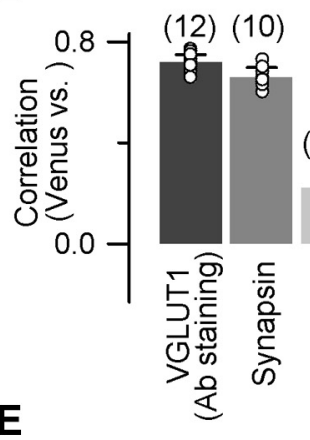

\section{Cortex}

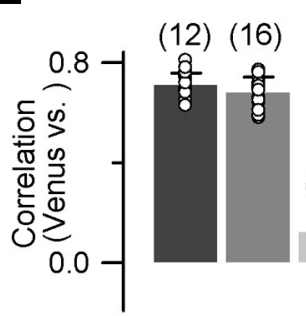

(16)

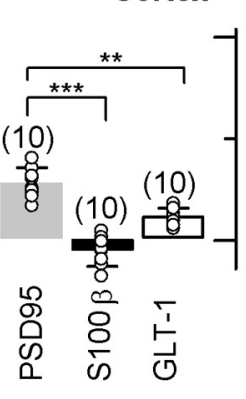

Hippocampus

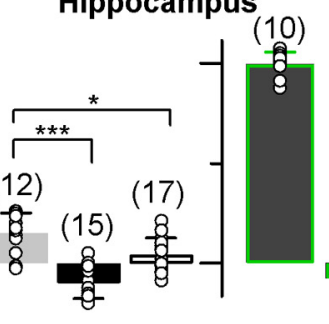

(9)

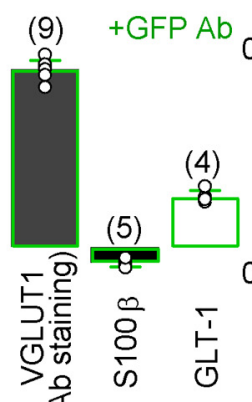

Venus vs.
F

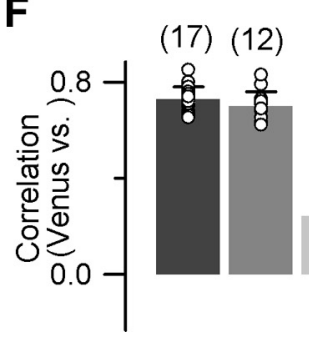

\section{Cerebellum}

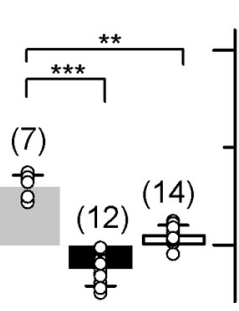

(11)

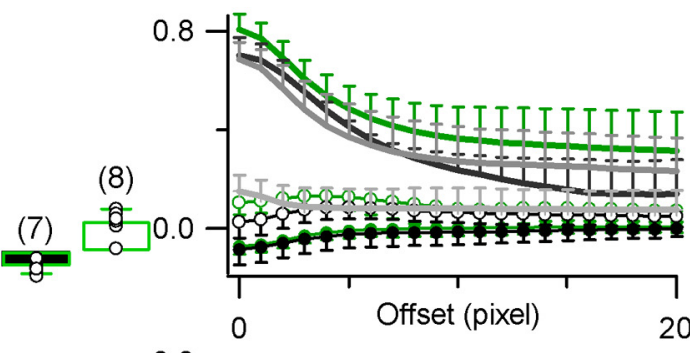

20 
were obtained in the neuropil of the CA1, CA3, and dentate regions of the hippocampus (Fig. 8A-C) and in the molecular (ML) and granule cell (GL) layers of the cerebellum (Fig. $8 D-F$ ). In both hippocampal and cerebellar regions, the VGLUT1/synapsin line profiles overlapped (Fig. $8 A, D$, right) and showed high Pearson's correlation coefficient values $\left(r_{12}=0.72 \pm 0.05, n=23\right.$ in hippocampus, Fig. $8 B ; r_{12}=0.71 \pm 0.05, n=12$ in cerebellum, Fig. $8 E$ ), which were quickly reduced by pixel shift (Fig. $8 C, F$ ), as expected for overlapping correlated distributions of VGLUT1 and synapsin. The VGLUT1/PSD-95 line profiles were slightly shifted compared with VGLUT1/synapsin in both hippocampus and cerebellum (Fig. $8 A, D$, right), their correlation coefficients were smaller $\left(r_{12}=0.19 \pm 0.09, n=4\right.$ in hippocampus, Fig. $8 B$; $r_{12}=0.38 \pm 0.06, n=6$ in cerebellum, Fig. $8 E$ ) and reduced by pixel shift (Fig. $8 C, F$ ). In neither region, the VGLUT1/S100 $\beta$ line profiles were superimposed (Fig. $8 A, D$, left) and the correlation coefficient values were negative $\left(r_{12}=-0.07 \pm 0.08\right.$, pooled value for hippocampus; $r_{12}=-0.09 \pm 0.1$ for cerebellum, respectively; Fig. $8 B, E$ ), significantly different from the VGLUT1/ PSD-95 coefficient, and barely affected by pixel shift (Fig. 8C,F), indicating uncorrelated distributions of VGLUT1 and $\$ 100 \beta$. In both regions, the VGLUT1/GLT-1 and VGLUT1/AQ4 line profiles were not superimposed (Fig. $8 A, D$, middle), and their weakly positive $r_{12}$ values close to or lower than the VGLUT1/ PSD-95 coefficient $\left(r_{12}=0.16 \pm 0.1\right.$, pooled value for hippocampus; $r_{12}=0.15 \pm 0.08$ for cerebellum, respectively; Fig. $8 B, E$ ). The $r_{12}$ value of VGLUT1/GLT-1 was not affected by pixel shift, as similarly observed for VGLUT1/AQ4 (Fig. 8C,F), indicating uncorrelated distributions between VGLUT1 and astrocytic membrane markers GLT-1 and AQ4. Together, these results using brain slices, immunostaining, and confocal microscopy do not provide evidence for the expression of VGLUT1 by $\mathrm{S} 100 \beta$, GLT-1, or AQ4-positive astrocytic processes of the cortex, hippocampus, and cerebellum.

Finally we investigated a possible colocalization of the astrocytic markers, GLT-1 and S100 $\beta$, with VGLUT1 using Tg VGLUT1 ${ }^{\text {Venus }}$ KI mice (Herzog et al., 2011). The correlation between the distribution of Venus and the neuronal (VGLUT1, synapsin, PSD-95) or astrocytic (S100 $\beta$, GLT-1) markers was quantified in fixed cortical, hippocampal, and cerebellar slices (Fig. 9). We first examined the specificity of the Venus expression using antibodies against three neuronal proteins (VGLUT1, synapsin, and PSD-95). Low-magnification confocal images confirmed that Venus and VGLUT1 were similarly distributed in the hippocampus (Fig. 9A). The colocalization between Venus/ VGLUT1 and Venus/synapsin is evident from their overlapping line profiles (Fig. $9 B$ ), the high positive correlation $\left(r_{12}=0.72 \pm\right.$ 0.04 , pooled value from all regions for Venus/VGLUT1; $r_{12}=$ $0.68 \pm 0.05$ for Venus/synapsin), and the swift decrease of $r_{12}$ values upon pixel shift (Fig. 9D-F). Similar results were obtained when we quantified the Venus fluorescence itself (Fig. 9D-F, black labels) and when its fluorescence was enhanced by Venus immunostaining using an antibody against GFP (Fig. 9D-F, green labels). These control experiments confirm the specific targeting of Venus to VGLUT1-positive synapses (Herzog et al.,

$\leftarrow$

(Figure legend continued.) plot (right). Along with directly imaging Venus fluorescence, we also used an antibody against GFP to increase the Venus signal. Similar results were obtained with (green outline) and without the GFP antibody, confirming that the Venus fluorescence itself is strong enough for quantitative imaging. Similar experiment and analysis were performed for cortical $(\boldsymbol{D})$, hippocampal $(\boldsymbol{E})$, and cerebellar $(\boldsymbol{F})$ regions. Two VGLUT1 ${ }^{\text {Venus }} \mathrm{KI}$ mice were used.
2011). Our data show also that Venus/PSD-95 and VGLUT1/ PSD-95 colocalization parameters are indistinguishable. However, by the same analysis, we found no evidence for colocalization between Venus and the two astrocyte markers, S100 $\beta$ and GLT-1. In fact, in all brain regions studied (Fig. 9D-F), the Venus/S100 $\beta$ correlation coefficient was negative and significantly lower than the Venus/PSD-95 coefficient $\left(r_{12}=0.22 \pm 0.06, n=10\right.$, cortex; $r_{12}=$ $0.12 \pm 0.08, n=12$, hippocampus; $r_{12}=0.24 \pm 0.05, n=7$, cerebellum), as was the Venus/GLT- 1 coefficient $\left(r_{12}=0.093 \pm 0.03\right.$, $n=10$, cortex; $r_{12}=0.038 \pm 0.064, n=17$, hippocampus; $r_{12}=$ $0.045 \pm 0.037, n=14$, cerebellum). Again, these results using VGLUT1 ${ }^{\text {Venus }}$ KI mice, immunostaining, and confocal microscopy do not provide any argument in favor of the expression VGLUT1 by the $S 100 \beta$ or GLT-1-positive astrocytic processes.

\section{VGLUT2 expression in brain slices}

The expression of VGLUT2 in the forebrain is sparse and mostly found at VGLUT1-negative synapses. Since VGLUT2 is found in the lemniscal axonal endings in the VB thalamic nucleus (Fremeau et al., 2001; Herzog et al., 2001; Sakata-Haga et al., 2001), the thalamocortical axonal endings in the layer 4 S1 barrel cortex (Nakamura et al., 2005; Graziano et al., 2008), and the climbing fibers in the cerebellum (Hioki et al., 2003; Boulland et al., 2004; Mandolesi et al., 2009), we compared the distribution of VGLUT2, S100 $\beta$, and GLT-1 in the thalamic VB nucleus, layer 4 barrel cortex, and cerebellum, using neuronal and astrocytic markers and high-magnification confocal immunofluorescence imaging (Fig. 10).

Using the same type of pixel-based colocalization analysis, we found no evidence for VGLUT2/synapsin colocalization in these regions (Fig. 10D-F). Thus, VGLUT2- and VGLUT1-positive synapses that express different SNARE proteins (Mandolesi et al., 2009), probably express also different regulatory synaptic proteins, such as synapsin, which was detected only at VGLUT1positive synapses. As a consequence we could not use the VGLUT2/synapsin Pearson's values as a positive control. Instead, we used the VGLUT1/synapsin correlation values found in both cortex (Fig. 7) and hippocampus (Fig. 8A,B). In the thalamic VB nucleus where VGLUT1 is expressed by the synapses of cortical origin (Graziano et al., 2008), we found overlapping VGLUT1 and synapsin fluorescence profiles (Fig. 10B), a correlated scatter plot (Fig. 10C), and a high correlation that rapidly dwindled when introducing a pixel shift between the VGLUT1 and synapsin images $\left(r_{12}=0.74 \pm 0.01, n=5\right.$, Fig. $\left.10 D\right)$. Finally, as in the cortex (Fig. 7) and hippocampus (Fig. $8 A, B$ ), in the VB nucleus, we found nonoverlapping VGLUT1 and PSD-95 fluorescence profiles (Fig. 10B), a weakly correlated scatter plot (Fig. 10C), and a Pearson's value that was relatively weak and immediately reduced by pixel shift $\left(r_{12}=0.19 \pm 0.04, n=5\right.$, Fig. $\left.10 D\right)$, as expected for proteins expressed by two nearby distinct compartments. Therefore we used VGLUT1/synapsin as a positive control (+CTR), and VGLUT1/PSD-95 as a negative control (-CTR) for quantifying protein distributions (Fig. $10 D-F$ ). In the same brain regions, VGLUT2/S100 $\beta$ and VGLUT2/GLT-1 fluorescence profiles (Fig. 10A), scatter plots (Fig. 10C), and correlation analysis (Fig. 10D-F) did not lend any support to a colocalization between VGLUT2 and the astrocyte markers, S100 $\beta$ and GLT-1. Their correlation was indistinguishable from the negative control. Our results indicate that neither the astrocytes in the thalamic VB nucleus, nor in the layer 4 barrel cortex, nor in the cerebellum express VGLUT2. 
A VGLUT2 S100B
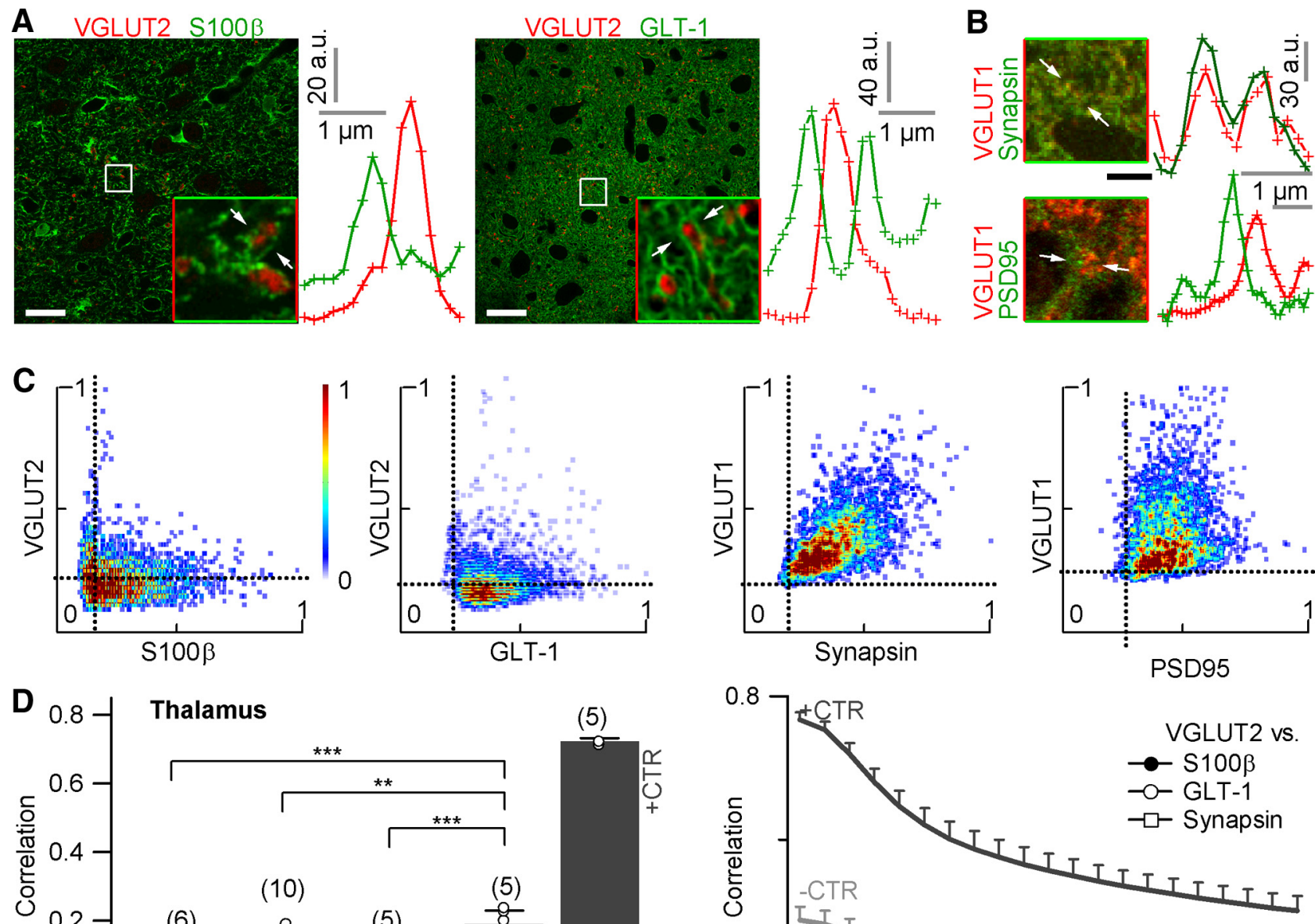

Thalamus

(5)

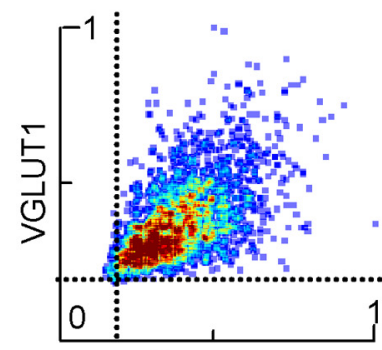

Synapsin
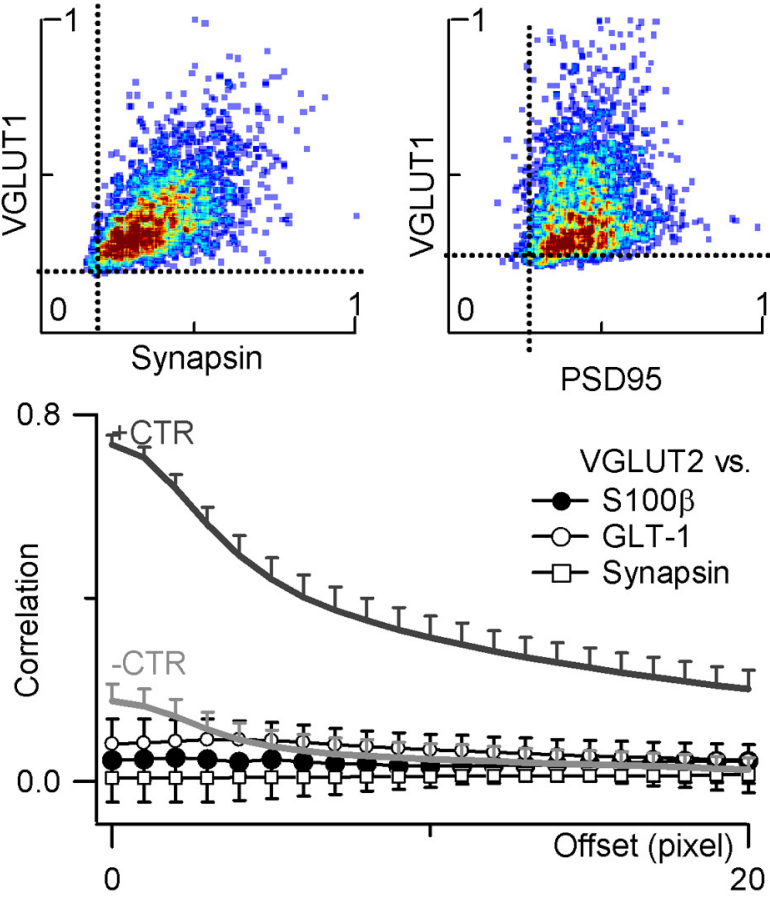

$E$
0
$\frac{0}{0}$
$\frac{\pi}{0}$
0
0
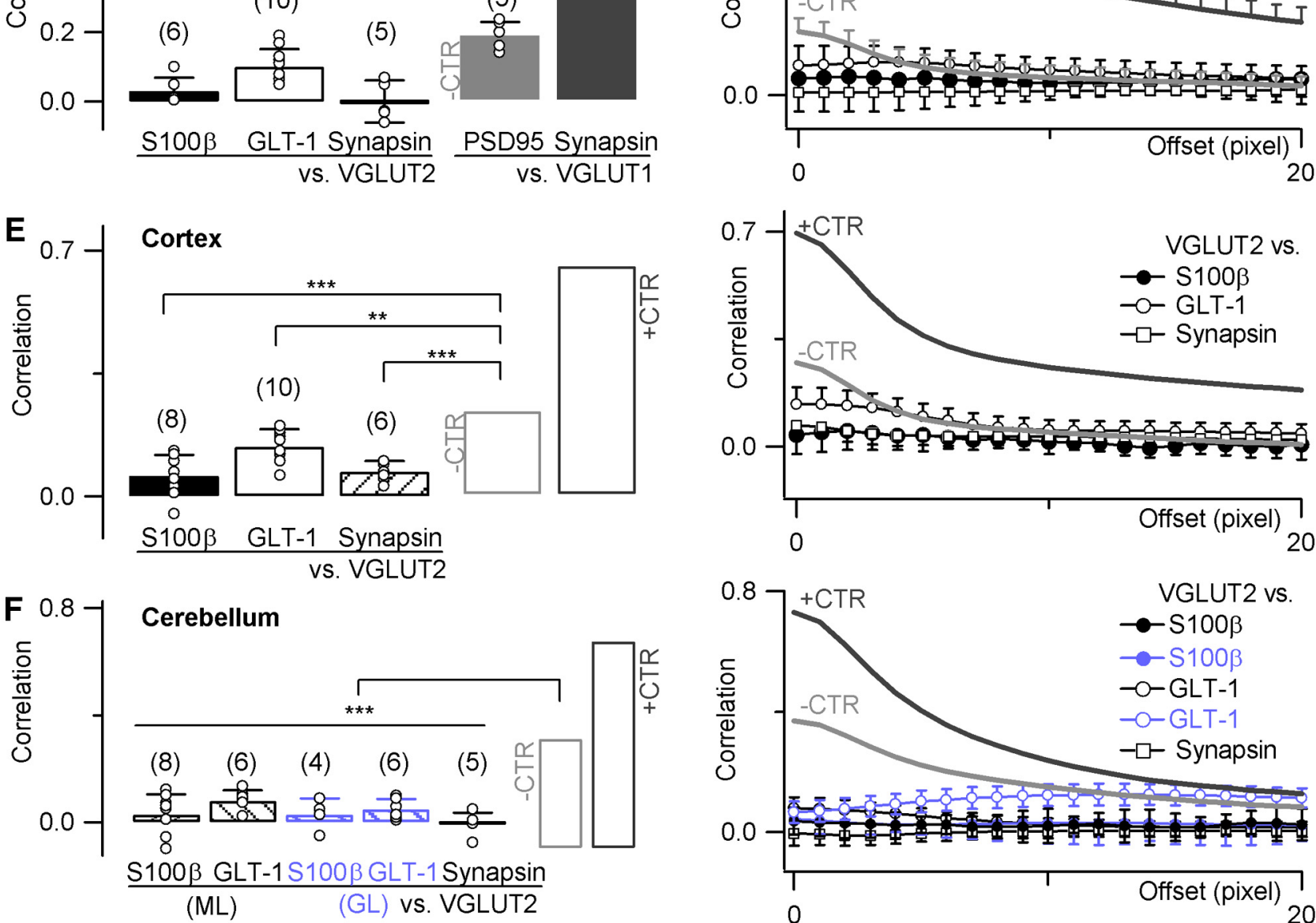

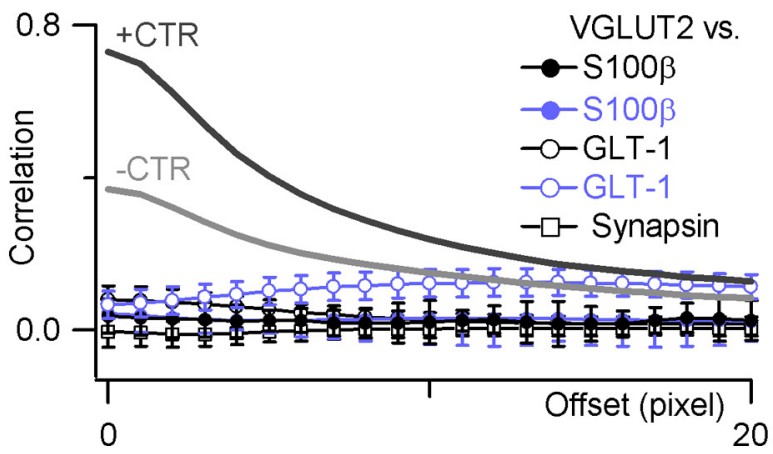

Figure 10. VGLUT2 and astrocytic markers do not colocalize. $\boldsymbol{A}$, Dual-color high-magnification confocal images in the VB thalamic nucleus immunostained with antibodies against VGLUT2, synapsin, PSD-95, S100 $\beta$, and GLT-1. Scale bars, $20 \mu \mathrm{m}$. B, Magnified ROI in the VB thalamic nucleus immunostained with antibodies against VGLUT1 and synapsin for positive (Figure legend continues.) 


\section{VGLUT3 expression in brain slices}

Unlike VGLUT1 and VGLUT2, VGLUT3 is expressed by cells that are not recognized as conventional glutamatergic neurons such as the raphe serotonergic neurons, the striatal cholinergic neurons, and subtypes of hippocampal and cortical GABAergic interneurons (Fremeau et al., 2002; Gras et al., 2002; Schäfer et al., 2002; Somogyi et al., 2004). VGLUT3 is also expressed by nonneuronal cells such as inner hair cells of the ear (Ruel et al., 2008; Seal et al., 2008), where its mutation or its genetic inactivation leads to deafness. Interestingly, VGLUT3 inactivation leads to cortical hyperexcitability and to a deficit of neuronal growth (Seal et al., 2008). Finally, a putative astrocytic expression of VGLUT3 (Fremeau et al., 2002; Ormel et al., 2012a) is still controversial since Western blot analysis was unable to demonstrate the expression of VGLUT3 in the cerebellum (Gras et al., 2002).

To investigate the possible expression of VGLUT3 by astrocytes in situ, we compared the distributions of VGLUT3, S100 $\beta$, and GLT-1 in hippocampal and cortical slices (Fig. 11). We used the mean VGLUT1/synapsin and VGLUT1/PSD-95 correlation coefficients as positive (+CTR) and negative ( - CTR) controls, respectively (Fig. 11C,D). Neither VGLUT3/GLT-1 (Fig. 11A) nor VGLUT3/S100 $\beta$ intensity profiles showed overlap (Fig. 11B). The VGLUT3/S100 $\beta$ correlation was close to zero in hippocampal $\left(r_{12}=0.005 \pm 0.02, n=13\right)$ and cortical $\left(r_{12}=0.03 \pm 0.04\right.$, $n=6)$ regions, being significantly lower than the VGLUT1/ PSD-95 negative controls $\left(r_{12}=0.19 \pm 0.09, n=4\right.$ in hippocampus; $r_{12}=0.25 \pm 0.06, n=12$, in cortex; $p<0.001$; Fig. $\left.11 C, D\right)$. The VGLUT3/S100 $\beta$ coefficient was also unchanged upon pixel shift, indicating a lack of correlation between VGLUT3 and S100 $\beta$. Likewise, the weak correlation between cortical VGLUT3 and GLT-1 signals was significantly smaller than the VGLUT1/ PSD-95 control. In the hippocampus, no difference was found between VGLUT3/GLT-1 and VGLUT1/PSD-95 correlation coefficients. Together, these results do not provide any evidence for the colocalization VGLUT3 with S100 $\beta$ or GLT-1, suggesting that neither cortical nor hippocampal astrocytes express VGLUT3 in situ.

\section{Discussion}

Our data provide no evidence in favor of the expression of any of the three vesicular glutamate transporters (VGLUT1-3) by the gray matter protoplasmic astrocytes found in the primary somatosensory cortex and the thalamic VB nucleus, as well as the hippocampus and the cerebellum. We first used VGLUT1-3 KO mice, VGLUT1 ${ }^{\text {Venus }} \mathrm{KI}$, immunostaining, and Western blots, and we could not detect the expression of VGLUT1-3 in cortical and thalamic astrocytes in culture (Figs. 1-5). Second, using immunostaining and confocal imaging of brain slices, we quantified the degree of overlap between VGLUT1-3 and neuronal or astrocytic markers with fluorescence line profiles, dual-color scatter plots, and Pearson's correlation coefficient analysis, again finding

\section{$\leftarrow$}

(Figure legend continued.) control (+CTR), and against VGLUT1 and PSD-95 for negative control (-CTR). Scale bar, $5 \mu \mathrm{m}$. C, Density-coded scatter plots illustrating the correlation between pixel intensities of different pairs of markers. $\boldsymbol{D}-\boldsymbol{F}$, Pearson's correlation coefficient analysis and the offset-correlation plot quantifying the colocalization between VGLUT2 and astrocytic markers in thalamic (D), cortical $(\boldsymbol{E})$, and cerebellar $(\boldsymbol{F})$ slices. Unlike VGLUT1, VGLUT2 shows low colocalization with synapsin. In cortical and cerebellar regions, the mean value of +CTR and - CTR is taken from VGLUT1 experiments (Figs. 7, 8), and the error bars omitted for clarity. Two animals were used for each VGLUT2 experiment, and one animal used forVGLUT1synapsin/PSD-95 experiment in thalamus. no evidence for colocalization between VGLUT1-3 and astrocytic markers (Figs. 6-11).

\section{Astrocytes in culture do not express VGLUT1-3}

Our experiments confirmed earlier observation that immunostaining against VGLUT1 (Montana et al., 2004; Zhang et al., 2004; Anlauf and Derouiche, 2005; Bowser and Khakh, 2007; Stenovec et al., 2007; Marchaland et al., 2008) and VGLUT2 (Montana et al., 2004; Anlauf and Derouiche, 2005; Crippa et al., 2006; Ni and Parpura, 2009) labels astrocytes in culture (Figs. 1, 4). Similar immunostaining was observed with VGLUT3 antibodies (Fig. 5). However, for all three VGLUTs the immunostaining was relatively weak and unaffected by the genetic ablation of the VGLUTs, indicating that the astrocytes in culture lack VGLUT1-3, and that the faint punctate labeling was not specific. The lack of VGLUT1 expression by the astrocytes in culture was also confirmed using live-cell TIRFM showing the absence of Venus-positive vesicles in the astrocytes in culture prepared from VGLUT1 ${ }^{\text {Venus }}$ KI mice (Fig. 2). Finally, no evidence for VGLUT2 expression could be obtained in the cultured astrocytes from the Tg Bac VGLUT2-EGFP mice (Fig. 3).

\section{VGLUT1-3 immunofluorescence does not correlate with astrocytic markers in cortical slices}

We used the Pearson's correlation coefficient to quantify the spatial correlation between VGLUT1-3, and various neuronal or astrocytic markers in situ using confocal images of fixed brain slices. First, our control experiments with antibodies against three astrocytic proteins $\left(\mathrm{S} 100 \beta\right.$, a cytosolic $\mathrm{Ca}^{2+}$ binding protein; GLT-1, a transmembrane glutamate transporter; AQ4, a transmembrane water-permeable channel), which label the thin astrocytic processes, demonstrated overlapping fluorescence profiles and high correlation that rapidly dropped with pixel shift in all regions investigated, as expected for proteins expressed by the thin subdiffraction astrocytic processes (Fig. 6). Second, to estimate meaningful upper (+CTR) and lower (-CTR) boundaries of our correlation estimates, we performed dual-color immunostaining with antibodies against VGLUT1 and the presynaptic marker synapsin (+CTR), or the postsynaptic density marker PSD-95 (-CTR). Our results show that our method is able to distinguish between true colocalization of VGLUT1 and synapsin, and diffraction-limited partial overlap of VGLUT1 and PSD-95 fluorescence signal. The VGLUT1/synapsin fluorescence profiles showed complete overlap, with linear dual-color scatter plots, and maximal Pearson's values that were quickly reduced by pixel shift (Figs. 7-10). The VGLUT1/PSD-95 fluorescence showed nonoverlapping profiles with distorted dual-color scatter plots, and smaller correlation coefficients that were nonetheless reduced by pixel shift (Figs. 7-10). These results show that our quantification analysis can distinguish truly overlapping compartments and nonoverlapping diffraction-limited neuronal and astroglial compartments found at the tripartite synapse (Ventura and Harris, 1999; Genoud et al., 2006).

A recurrent result of our study is the lack of overlap between the three VGLUTs and three astrocytic markers, S100 $\beta$, GLT-1, and AQ4. Pearson's correlation coefficients between all three VGLUT1-3 proteins and the astrocytic cytosolic marker S100 $\beta$ were close to zero and significantly smaller than the negative controls (-CTR) of our colocalization analysis (Figs. 7-10), indicating that the VGLUT1-3 proteins do not locate within the astrocytic cytosol in all regions we examined. This conclusion has been further confirmed by the absence of a steep reduction of the VGLUT/S100 $\beta$ Pearson's correlation coefficient upon pixel shift, 
A
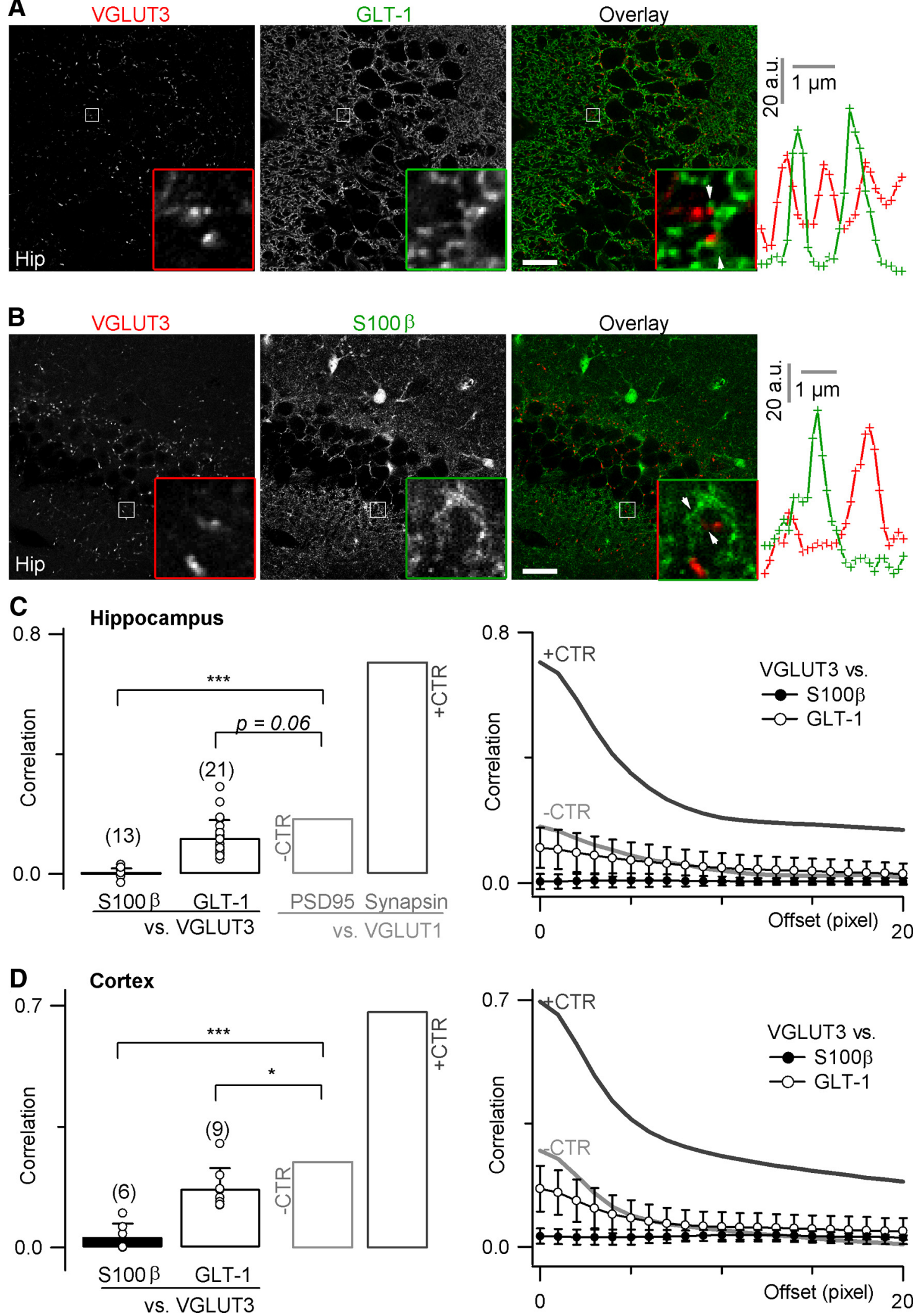

Figure 11. VGLUT3 and astrocytic markers do not colocalize. Dual-color high-magnification confocal images in hippocampal slices coimmunostained with antibodies against VGLUT3 and GLT-1 in the CA3 region $(A)$, and against VGLUT3 and S100 $\beta$ in CA1 region (B). Scale bars: $20 \mu \mathrm{m}$. C, D, Quantitative colocalization analysis using Pearson's correlation coefficient and the offset-correlation plot in hippocampus ( $\boldsymbol{C}$ ) and cortex (D). The mean values of VGLUT1/synapsin (+CTR) and VGLUT1/PSD-95 (-CTR) were taken from VGLUT1 experiments (Figs. 7,8). Number of analyzed regions in one mouse is indicated above each bar. 
which rather shows no change or, if any, a slight increase, implying proximity or a loose apposition, rather than colocalization, between the VGLUT proteins and S100 $\beta$-positive astrocytic processes, as expected from electron micrographs (Ventura and Harris, 1999; Genoud et al., 2006). Our results comparing the distribution of VGLUTs and the astrocytic transmembrane protein, GLT-1 and AQ4, were slightly different, but they also failed to show overlap between VGLUT proteins and GLT-1/AQ4positive astrocytic processes. The correlation coefficients with VGLUT labeling were larger for membrane proteins GLT-1 and AQ4 than for the cytoplasmic $\mathrm{Ca}^{2+}$-binding protein $\mathrm{S} 100 \beta$, but they failed to exceed the level of the VGLUT1/PSD-95-negative control, and their offset-correlation plots were unchanged with pixel shift (Figs. 7, 8B, 9, 10). Thus, the low correlation coefficient between VGLUT and astrocytic membrane markers GLT-1 and AQ4 is likely to reflect the diffraction limit-induced overlap of the fluorescence of the two types of proteins that reside in two distinct compartments separated by a distance below the spatial resolution of confocal microscopy, as expected by the proximity between astrocytic membrane and the presynaptic compartment (Ventura and Harris, 1999; Genoud et al., 2006).

In conclusion, our results from brain slices provide no evidence that VGLUT proteins are present in astrocytes in situ. Thus the global pixel-based analysis corroborates our single-vesicle data from cultured astrocytes. Together, our results therefore call into reconsideration the molecular mechanism by which astrocytes participate in the glutamate-mediated astrocyte-to-neuron signal at tripartite synapse. $\mathrm{Ca}^{2+}$-regulated lysosomal exocytosis identified in astrocytes (Zhang et al., 2007; Li et al., 2008) is one possible candidate pathway for glutamate exocytosis since the lysosomal sialic acid transporter, sialin, has been reported to behave as an aspartate/glutamate transporter that accumulates the amino acids inside the vesicular compartment (Miyaji et al., 2008). However lysosomal exocytosis operates on a timescale much slower than the $\mathrm{Ca}^{2+}$-dependent exocytosis recorded in astrocytes (Bezzi et al., 2004; Zhang et al., 2007; Li et al., 2008; Marchaland et al., 2008). Other routes for glutamate release from astrocytes have been suggested, such as hemichannels (Ye et al., 2003), anion channels (Takano et al., 2005; Kimelberg et al., 2006; Park et al., 2009; Li et al., 2012), and reversed glutamate transport (Rossi et al., 2000). Their possible participation in various physiological and pathological conditions will require more studies (Cali et al., 2009; Fiacco et al., 2009; Perea et al., 2009; Halassa and Haydon, 2010; Hamilton and Attwell, 2010).

\section{References}

Anlauf E, Derouiche A (2005) Astrocytic exocytosis vesicles and glutamate: a high-resolution immunofluorescence study. Glia 49:96-106. Medline

Araque A, Parpura V, Sanzgiri RP, Haydon PG (1999) Tripartite synapses: glia, the unacknowledged partner. Trends Neurosci 22:208-215. CrossRef Medline

Bai L, Xu H, Collins JF, Ghishan FK (2001) Molecular and functional analysis of a novel neuronal vesicular glutamate transporter. J Biol Chem 276:36764-36769. CrossRef Medline

Bellocchio EE, Reimer RJ, Fremeau RT Jr, Edwards RH (2000) Uptake of glutamate into synaptic vesicles by an inorganic phosphate transporter. Science 289:957-960. CrossRef Medline

Bergersen LH, Morland C, Ormel L, Rinholm JE, Larsson M, Wold JF, Røe AT, Stranna A, Santello M, Bouvier D, Ottersen OP, Volterra A, Gundersen V (2012) Immunogold detection of L-glutamate and D-serine in small synaptic-like microvesicles in adult hippocampal astrocytes. Cereb Cortex 22:1690-1697. Medline

Bezzi P, Gundersen V, Galbete JL, Seifert G, Steinhäuser C, Pilati E, Volterra A (2004) Astrocytes contain a vesicular compartment that is competent for regulated exocytosis of glutamate. Nat Neurosci 7:613-620. CrossRef Medline
Binder DK, Nagelhus EA, Ottersen OP (2012) Aquaporin-4 and epilepsy. Glia 60:1203-1214. CrossRef Medline

Boulland JL, Qureshi T, Seal RP, Rafiki A, Gundersen V, Bergersen LH, Fremeau RT Jr, Edwards RH, Storm-Mathisen J, Chaudhry FA (2004) Expression of the vesicular glutamate transporters during development indicates the widespread corelease of multiple neurotransmitters. J Comp Neurol 480:264-280. CrossRef Medline

Bowser DN, Khakh BS (2007) Two forms of single-vesicle astrocyte exocytosis imaged with total internal reflection fluorescence microscopy. Proc Natl Acad Sci U S A 104:4212-4217. CrossRef Medline

Cahoy JD, Emery B, Kaushal A, Foo LC, Zamanian JL, Christopherson KS, Xing Y, Lubischer JL, Krieg PA, Krupenko SA, Thompson WJ, Barres BA (2008) A transcriptome database for astrocytes, neurons, and oligodendrocytes: a new resource for understanding brain development and function. J Neurosci 28:264-278. CrossRef Medline

Calì C, Marchaland J, Spagnuolo P, Gremion J, Bezzi P (2009) Regulated exocytosis from astrocytes physiological and pathological related aspects. Int Rev Neurobiol 85:261-293. CrossRef Medline

Chaudhry FA, Lehre KP, van Lookeren Campagne M, Ottersen OP, Danbolt NC, Storm-Mathisen J (1995) Glutamate transporters in glial plasma membranes: highly differentiated localizations revealed by quantitative ultrastructural immunocytochemistry. Neuron 15:711-720. CrossRef Medline

Crippa D, Schenk U, Francolini M, Rosa P, Verderio C, Zonta M, Pozzan T, Matteoli M, Carmignoto G (2006) Synaptobrevin2-expressing vesicles in rat astrocytes: insights into molecular characterization, dynamics and exocytosis. J Physiol 570:567-582. Medline

Fiacco TA, Agulhon C, McCarthy KD (2009) Sorting out astrocyte physiology from pharmacology. Annu Rev Pharmacol Toxicol 49:151-174. CrossRef Medline

Fremeau RT Jr, Troyer MD, Pahner I, Nygaard GO, Tran CH, Reimer RJ, Bellocchio EE, Fortin D, Storm-Mathisen J, Edwards RH (2001) The expression of vesicular glutamate transporters defines two classes of excitatory synapse. Neuron 31:247-260. CrossRef Medline

Fremeau RT Jr, Burman J, Qureshi T, Tran CH, Proctor J, Johnson J, Zhang H, Sulzer D, Copenhagen DR, Storm-Mathisen J, Reimer RJ, Chaudhry FA, Edwards RH (2002) The identification of vesicular glutamate transporter 3 suggests novel modes of signaling by glutamate. Proc Natl Acad Sci U S A 99:14488-14493. CrossRef Medline

Fremeau RT Jr, Voglmaier S, Seal RP, Edwards RH (2004a) VGLUTs define subsets of excitatory neurons and suggest novel roles for glutamate. Trends Neurosci 27:98-103. CrossRef Medline

Fremeau RT Jr, Kam K, Qureshi T, Johnson J, Copenhagen DR, StormMathisen J, Chaudhry FA, Nicoll RA, Edwards RH (2004b) Vesicular glutamate transporters 1 and 2 target to functionally distinct synaptic release sites. Science 304:1815-1819. CrossRef Medline

Fritschy JM (2008) Is my antibody-staining specific? How to deal with pitfalls of immunohistochemistry. Eur J Neurosci 28:2365-2370. CrossRef Medline

Genoud C, Quairiaux C, Steiner P, Hirling H, Welker E, Knott GW (2006) Plasticity of astrocytic coverage and glutamate transporter expression in adult mouse cortex. PLoS Biol 4:e343. CrossRef Medline

Gillespie DC, Kim G, Kandler K (2005) Inhibitory synapses in the developing auditory system are glutamatergic. Nat Neurosci 8:332-338. CrossRef Medline

Gong S, Zheng C, Doughty ML, Losos K, Didkovsky N, Schambra UB, Nowak NJ, Joyner A, Leblanc G, Hatten ME, Heintz N (2003) A gene expression atlas of the central nervous system based on bacterial artificial chromosomes. Nature 425:917-925. CrossRef Medline

Gras C, Herzog E, Bellenchi GC, Bernard V, Ravassard P, Pohl M, Gasnier B, Giros B, El Mestikawy S (2002) A third vesicular glutamate transporter expressed by cholinergic and serotoninergic neurons. J Neurosci 22:54425451. Medline

Gras C, Amilhon B, Lepicard EM, Poirel O, Vinatier J, Herbin M, Dumas S, Tzavara ET, Wade MR, Nomikos GG, Hanoun N, Saurini F, Kemel ML, Gasnier B, Giros B, El Mestikawy S (2008) The vesicular glutamate transporter VGLUT3 synergizes striatal acetylcholine tone. Nat Neurosci 11:292-300. CrossRef Medline

Graziano A, Liu XB, Murray KD, Jones EG (2008) Vesicular glutamate transporters define two sets of glutamatergic afferents to the somatosensory thalamus and two thalamocortical projections in the mouse. J Comp Neurol 507:1258-1276. CrossRef Medline 
Halassa MM, Haydon PG (2010) Integrated brain circuits: astrocytic networks modulate neuronal activity and behavior. Annu Rev Physiol 72: 335-355. CrossRef Medline

Hamilton NB, Attwell D (2010) Do astrocytes really exocytose neurotransmitters? Nat Rev Neurosci 11:227-238. CrossRef Medline

Hayashi M, Otsuka M, Morimoto R, Hirota S, Yatsushiro S, Takeda J, Yamamoto A, Moriyama Y (2001) Differentiation-associated Na+dependent inorganic phosphate cotransporter (DNPI) is a vesicular glutamate transporter in endocrine glutamatergic systems. J Biol Chem 276: 43400-43406. CrossRef Medline

Heller EA, Zhang W, Selimi F, Earnheart JC, Ślimak MA, Santos-Torres J, Ibañez-Tallon I, Aoki C, Chait BT, Heintz N (2012) The biochemical anatomy of cortical inhibitory synapses. PLoS One 7:e39572. CrossRef Medline

Herzog E, Bellenchi GC, Gras C, Bernard V, Ravassard P, Bedet C, Gasnier B, Giros B, El Mestikawy S (2001) The existence of a second vesicular glutamate transporter specifies subpopulations of glutamatergic neurons. J Neurosci 21:RC181. Medline

Herzog E, Gilchrist J, Gras C, Muzerelle A, Ravassard P, Giros B, Gaspar P, El Mestikawy S (2004) Localization of VGLUT3, the vesicular glutamate transporter type 3, in the rat brain. Neuroscience 123:983-1002. CrossRef Medline

Herzog E, Nadrigny F, Silm K, Biesemann C, Helling I, Bersot T, Steffens H, Schwartzmann R, Nägerl UV, El Mestikawy S, Rhee J, Kirchhoff F, Brose $\mathrm{N}$ (2011) In vivo imaging of intersynaptic vesicle exchange using VGLUT1 Venus knock-in mice. J Neurosci 31:15544-15559. CrossRef Medline

Hioki H, Fujiyama F, Taki K, Tomioka R, Furuta T, Tamamaki N, Kaneko T (2003) Differential distribution of vesicular glutamate transporters in the rat cerebellar cortex. Neuroscience 117:1-6. CrossRef Medline

Hnasko TS, Edwards RH (2012) Neurotransmitter corelease: mechanism and physiological role. Annu Rev Physiol 74:225-243. CrossRef Medline

Hunt CA, Schenker LJ, Kennedy MB (1996) PSD-95 is associated with the postsynaptic density and not with the presynaptic membrane at forebrain synapses. J Neurosci 16:1380-1388. Medline

Huttner WB, Schiebler W, Greengard P, De Camilli P (1983) Synapsin I (protein I), a nerve terminal-specific phosphoprotein. III. Its association with synaptic vesicles studied in a highly purified synaptic vesicle preparation. J Cell Biol 96:1374-1388. CrossRef Medline

Juge N, Gray JA, Omote H, Miyaji T, Inoue T, Hara C, Uneyama H, Edwards RH, Nicoll RA, Moriyama Y (2010) Metabolic control of vesicular glutamate transport and release. Neuron 68:99-112. CrossRef Medline

Kimelberg HK, Macvicar BA, Sontheimer H (2006) Anion channels in astrocytes: biophysics, pharmacology, and function. Glia 54:747-757. CrossRef Medline

Li D, Ropert N, Koulakoff A, Giaume C, Oheim M (2008) Lysosomes are the major vesicular compartment undergoing $\mathrm{Ca} 2+$-regulated exocytosis from cortical astrocytes. J Neurosci 28:7648-7658. CrossRef Medline

Li D, Hérault K, Oheim M, Ropert N (2009) FM dyes enter via a storeoperated calcium channel and modify calcium signaling of cultured astrocytes. Proc Natl Acad Sci U S A 106:21960-21965. CrossRef Medline

Li D, Hérault K, Isacoff EY, Oheim M, Ropert N (2012) Optogenetic activation of LiGluR-expressing astrocytes evokes anion channel-mediated glutamate release. J Physiol 590:855-873. Medline

Mandolesi G, Vanni V, Cesa R, Grasselli G, Puglisi F, Cesare P, Strata P (2009) Distribution of the SNAP25 and SNAP23 synaptosomalassociated protein isoforms in rat cerebellar cortex. Neuroscience 164: 1084-1096. CrossRef Medline

Marchaland J, Calì C, Voglmaier SM, Li H, Regazzi R, Edwards RH, Bezzi P (2008) Fast subplasma membrane $\mathrm{Ca} 2+$ transients control exoendocytosis of synaptic-like microvesicles in astrocytes. J Neurosci 28: 9122-9132. CrossRef Medline

Miyaji T, Echigo N, Hiasa M, Senoh S, Omote H, Moriyama Y (2008) Identification of a vesicular aspartate transporter. Proc Natl Acad Sci U S A 105:11720-11724. CrossRef Medline

Moechars D, Weston MC, Leo S, Callaerts-Vegh Z, Goris I, Daneels G, Buist A, Cik M, van der Spek P, Kass S, Meert T, D'Hooge R, Rosenmund C, Hampson RM (2006) Vesicular glutamate transporter VGLUT2 expression levels control quantal size and neuropathic pain. J Neurosci 26: 12055-12066. CrossRef Medline

Montana V, Ni Y, Sunjara V, Hua X, Parpura V (2004) Vesicular glutamate transporter-dependent glutamate release from astrocytes. J Neurosci 24: 2633-2642. CrossRef Medline

Moriyama Y, Yamamoto A (2004) Glutamatergic chemical transmission: Look! Here, there, and anywhere. J Biochem 135:155-163. CrossRef Medline

Nadrigny F, Rivals I, Hirrlinger PG, Koulakoff A, Personnaz L, Vernet M, Allioux M, Chaumeil M, Ropert N, Giaume C, Kirchhoff F, Oheim M (2006) Detecting fluorescent protein expression and co-localisation on single secretory vesicles with linear spectral unmixing. Eur Biophys J 35: 533-547. CrossRef Medline

Nadrigny F, Li D, Kemnitz K, Ropert N, Koulakoff A, Rudolph S, Vitali M, Giaume C, Kirchhoff F, Oheim M (2007) Systematic colocalization errors between acridine orange and EGFP in astrocyte vesicular organelles. Biophys J 93:969-980. CrossRef Medline

Nakamura K, Hioki H, Fujiyama F, Kaneko T (2005) Postnatal changes of vesicular glutamate transporter (VGluT) 1 and VGluT2 immunoreactivities and their colocalization in the mouse forebrain. J Comp Neurol 492: 263-288. CrossRef Medline

Nedergaard M, Verkhratsky A (2012) Artifact versus reality-How astrocytes contribute to synaptic events? Glia 60:1013-1023. CrossRef Medline

Ni Y, Parpura V (2009) Dual regulation of Ca2+-dependent glutamate release from astrocytes: vesicular glutamate transporters and cytosolic glutamate levels. Glia 57:1296-1305. CrossRef Medline

Nielsen S, Nagelhus EA, Amiry-Moghaddam M, Bourque C, Agre P, Ottersen OP (1997) Specialized membrane domains for water transport in glial cells: high-resolution immunogold cytochemistry of aquaporin-4 in rat brain. J Neurosci 17:171-180. Medline

Nolte C, Matyash M, Pivneva T, Schipke CG, Ohlemeyer C, Hanisch UK, Kirchhoff F, Kettenmann H (2001) GFAP promoter-controlled EGFPexpressing transgenic mice: a tool to visualize astrocytes and astrogliosis in living brain tissue. Glia 33:72-86. CrossRef Medline

Ormel L, Stensrud MJ, Chaudhry FA, Gundersen V (2012a) A distinct set of synaptic-like microvesicles in astroglial cells contain VGLUT3. Glia 60: 1289-1300. CrossRef Medline

Ormel L, Stensrud MJ, Bergersen LH, Gundersen V (2012b) VGLUT1 is localized in astrocytic processes in several brain regions. Glia 60:229 238. CrossRef Medline

Park H, Oh SJ, Han KS, Woo DH, Park H, Mannaioni G, Traynelis SF, Lee CJ (2009) Bestrophin-1 encodes for the Ca2+-activated anion channel in hippocampal astrocytes. J Neurosci 29:13063-13073. CrossRef Medline

Perea G, Navarrete M, Araque A (2009) Tripartite synapses: astrocytes process and control synaptic information. Trends Neurosci 32:421-431. CrossRef Medline

Platel JC, Dave KA, Gordon V, Lacar B, Rubio ME, Bordey A (2010) NMDA receptors activated by subventricular zone astrocytic glutamate are critical for neuroblast survival prior to entering a synaptic network. Neuron 65:859-872. CrossRef Medline

Restani L, Antonucci F, Gianfranceschi L, Rossi C, Rossetto O, Caleo M (2011) Evidence for anterograde transport and transcytosis of botulinum neurotoxin A (BoNT/A). J Neurosci 31:15650-15659. CrossRef Medline

Rossi DJ, Oshima T, Attwell D (2000) Glutamate release in severe brain ischaemia is mainly by reversed uptake. Nature 403:316-321. CrossRef Medline

Ruel J, Emery S, Nouvian R, Bersot T, Amilhon B, Van Rybroek JM, Rebillard G, Lenoir M, Eybalin M, Delprat B, Sivakumaran TA, Giros B, El Mestikawy S, Moser T, Smith RJ, Lesperance MM, Puel JL (2008) Impairment of SLC17A8 encoding vesicular glutamate transporter-3, VGLUT3, underlies nonsyndromic deafness DFNA25 and inner hair cell dysfunction in null mice. Am J Hum Genet 83:278-292. CrossRef Medline

Sakata-Haga H, Kanemoto M, Maruyama D, Hoshi K, Mogi K, Narita M, Okado N, Ikeda Y, Nogami H, Fukui Y, Kojima I, Takeda J, Hisano S (2001) Differential localization and colocalization of two neuron-types of sodium-dependent inorganic phosphate cotransporters in rat forebrain. Brain Res 902:143-155. CrossRef Medline

Schäfer MK, Varoqui H, Defamie N, Weihe E, Erickson JD (2002) Molecular cloning and functional identification of mouse vesicular glutamate transporter 3 and its expression in subsets of novel excitatory neurons. J Biol Chem 277:50734-50748. CrossRef Medline

Seal RP, Akil O, Yi E, Weber CM, Grant L, Yoo J, Clause A, Kandler K, Noebels JL, Glowatzki E, Lustig LR, Edwards RH (2008) Sensorineural deafness and seizures in mice lacking vesicular glutamate transporter 3. Neuron 57:263-275. CrossRef Medline 
Somogyi J, Baude A, Omori Y, Shimizu H, El Mestikawy S, Fukaya M, Shigemoto R, Watanabe M, Somogyi P (2004) GABAergic basket cells expressing cholecystokinin contain vesicular glutamate transporter type 3 (VGLUT3) in their synaptic terminals in hippocampus and isocortex of the rat. Eur J Neurosci 19:552-569. CrossRef Medline

Stenovec M, Kreft M, Grilc S, Potokar M, Kreft ME, Pangrsic T, Zorec R (2007) Ca2+-dependent mobility of vesicles capturing anti-VGLUT1 antibodies. Exp Cell Res 313:3809-3818. CrossRef Medline

Takamori S, Rhee JS, Rosenmund C, Jahn R (2000) Identification of a vesicular glutamate transporter that defines a glutamatergic phenotype in neurons. Nature 407:189-194. CrossRef Medline

Takamori S, Rhee JS, Rosenmund C, Jahn R (2001) Identification of differentiation-associated brain-specific phosphate transporter as a second vesicular glutamate transporter (VGLUT2). J Neurosci 21:RC182. Medline

Takano T, Kang J, Jaiswal JK, Simon SM, Lin JH, Yu Y, Li Y, Yang J, Dienel G, Zielke HR, Nedergaard M (2005) Receptor-mediated glutamate release from volume sensitive channels in astrocytes. Proc Natl Acad Sci U S A 102:16466-16471. CrossRef Medline

Trudeau LE, Gutiérrez R (2007) On cotransmission and neurotransmitter phenotype plasticity. Mol Interv 7:138-146. CrossRef Medline

Varoqui H, Schäfer MK, Zhu H, Weihe E, Erickson JD (2002) Identification of the differentiation-associated $\mathrm{Na}+/ \mathrm{PI}$ transporter as a novel vesicular glutamate transporter expressed in a distinct set of glutamatergic synapses. J Neurosci 22:142-155. Medline

Ventura R, Harris KM (1999) Three-dimensional relationships between hippocampal synapses and astrocytes. J Neurosci 19:6897-6906. Medline

Vives V, Alonso G, Solal AC, Joubert D, Legraverend C (2003) Visualization of S100B-positive neurons and glia in the central nervous system of EGFP transgenic mice. J Comp Neurol 457:404-419. CrossRef Medline

Wojcik SM, Rhee JS, Herzog E, Sigler A, Jahn R, Takamori S, Brose N, Rosenmund C (2004) An essential role for vesicular glutamate transporter 1 (VGLUT1) in postnatal development and control of quantal size. Proc Natl Acad Sci U S A 101:7158-7163. CrossRef Medline

Ye ZC, Wyeth MS, Baltan-Tekkok S, Ransom BR (2003) Functional hemichannels in astrocytes: a novel mechanism of glutamate release. J Neurosci 23:3588-3596. Medline

Zhang Q, Pangrsic T, Kreft M, Krzan M, Li N, Sul JY, Halassa M, Van Bockstaele E, Zorec R, Haydon PG (2004) Fusion-related release of glutamate from astrocytes. J Biol Chem 279:12724-12733. Medline

Zhang Z, Chen G, Zhou W, Song A, Xu T, Luo Q, Wang W, Gu XS, Duan S (2007) Regulated ATP release from astrocytes through lysosome exocytosis. Nat Cell Biol 9:945-953. CrossRef Medline 